\title{
Poly(A) polymerase is required for RyhB sRNA stability and function in Escherichia coli
}

\author{
DHRITI SINHA, ${ }^{1}$ LISA M. MATZ, ${ }^{1}$ TODD A. CAMERON,${ }^{1}$ and NICHOLAS R. DE LAY ${ }^{1,2}$ \\ ${ }^{1}$ Department of Microbiology and Molecular Genetics, McGovern Medical School, University of Texas Health Science Center, Houston, \\ Texas 77030, USA \\ ${ }^{2} \mathrm{MD}$ Anderson Cancer Center UTHealth Graduate School of Biomedical Sciences, University of Texas Health Science Center, Houston, \\ Texas 77030, USA
}

\begin{abstract}
Small regulatory RNAs (sRNAs) are an important class of bacterial post-transcriptional regulators that control numerous physiological processes, including stress responses. In Gram-negative bacteria including Escherichia coli, the RNA chaperone $\mathrm{Hfq}$ binds many sRNAs and facilitates pairing to target transcripts, resulting in changes in mRNA transcription, translation, or stability. Here, we report that poly(A) polymerase (PAP I), which promotes RNA degradation by exoribonucleases through the addition of poly(A) tails, has a crucial role in the regulation of gene expression by $\mathrm{Hfq}$ dependent sRNAs. Specifically, we show that deletion of pcnB, encoding PAP I, paradoxically resulted in an increased turnover of certain Hfq-dependent sRNAs, including RyhB. RyhB instability in the pcnB deletion strain was suppressed by mutations in $h f q$ or ryhB that disrupt pairing of RyhB with target RNAs, by mutations in the $3^{\prime}$ external transcribed spacer of the glyW-cysT-leuZ transcript ( $3^{\prime} E T S^{\text {Leuz }}$ ) involved in pairing with RyhB, or an internal deletion in rne, which encodes the endoribonuclease RNase E. Finally, the reduced stability of RyhB in the pcnB deletion strain resulted in impaired regulation of some of its target mRNAs, specifically sodB and sdhCDAB. Altogether our data support a model where PAP I plays a critical role in ensuring the efficient decay of the $3^{\prime} E T S^{\text {LeuZ }}$. In the absence of PAP I, the $3^{\prime}$ ETS ${ }^{\text {LeuZ }}$ transcripts accumulate, bind $\mathrm{Hfq}$, and pair with RyhB, resulting in its depletion via RNase E-mediated decay. This ultimately leads to a defect in RyhB function in a PAP I deficient strain.
\end{abstract}

Keywords: poly(A) polymerase; penB; Hfq; small RNAs; RNase E

\section{INTRODUCTION}

Small regulatory RNAs (sRNAs) are transcripts ranging in size from 50 to 300 nucleotides (nt) that have been shown to regulate nearly every aspect of bacterial behavior and physiology including virulence (Toledo-Arana et al. 2009; Gripenland et al. 2010; Felden et al. 2011; Koo et al. 2011; Bardill and Hammer 2012; Hébrard et al. 2012; Mann et al. 2012; Rutherford and Bassler 2012; Caldelari et al. 2013; Holmqvist and Wagner 2017), biofilm development (Thomason et al. 2012; Jørgensen et al. 2013; Zhao et al. 2013; Parker et al. 2017), antibiotic resistance (Parker and Gottesman 2016; Zhang et al. 2017; Felden and Cattoir 2018), and metabolism (Durand and Storz 2010; Gimpel et al. 2010; Richards and Vanderpool 2011; Salvail and Massé 2012; Bobrovskyy and Vanderpool 2013; McClure et al. 2013; Mandin et al. 2016; Pannuri et al. 2016; Gonzalez et al. 2017). Many sRNAs regulate

Corresponding author: nicholas.r.delay@uth.tmc.edu

Article is online at http://www.rnajournal.org/cgi/doi/10.1261/rna. 067181.118. Freely available online through the RNA Open Access option. these processes by recognizing and binding specific target mRNAs through base-pairing resulting in changes in mRNA transcription, translation, or stability depending on the nature of this interaction. For example, sRNAs can inhibit translation by base-pairing with the mRNA translation initiation region directly blocking ribosome access to the Shine-Delgarno sequence (Møller et al. 2002a). Alternatively, negative regulation of gene expression can also be achieved by sRNA-induced RNase E mediated decay of mRNAs (Pfeiffer et al. 2009; Bandyra et al. 2012). Furthermore, sRNAs can positively regulate gene expression by base-pairing with a mRNA as it is being transcribed, preventing intramolecular base-pairing in the $5^{\prime}$ untranslated region ( $5^{\prime}$-UTR) that would otherwise lead to transcription attenuation (Sedlyarova et al. 2016).

In Escherichia coli and other Gram-negative bacteria, many sRNAs encoded in trans require the RNA-binding protein chaperone $\mathrm{Hfq}$ to function (Waters and Storz

(C) 2018 Sinha et al. This article, published in RNA, is available under a Creative Commons License (Attribution 4.0 International), as described at http://creativecommons.org/licenses/by/4.0/. 
2009; Storz et al. 2011). Hfq stabilizes sRNAs by binding and occluding an RNase E cleavage site (Moll et al. 2003), but also serves as a matchmaker by facilitating annealing between sRNAs and their target mRNAs (Møller et al. 2002b; Zhang et al. 2002; Lease and Woodson 2004; Soper and Woodson 2008). Although Hfq has been studied extensively, recent research has identified PNPase, encoding the $3^{\prime} \rightarrow 5^{\prime}$ exoribonuclease polynucleotide phosphorylase, as another mediator of sRNA stability and function (De Lay and Gottesman 2011). PNPase degrades at least some sRNAs not associated with $\mathrm{Hfa}$ (Viegas et al. 2007; Andrade et al. 2012). However, PNPase binds and stabilizes many Hfq-dependent sRNAs (Bandyra et al. 2016) and has been further shown to impact sRNA-mRNA pairing (Cameron and De Lay 2016).

The crucial role of PNPase in modulating sRNA stability and function was discovered in a combined genetic selection and screen designed to isolate mutants defective for sRNA function in E. coli. Loss-of-function point mutations identified in pnp interfered with target gene regulation by Hfq-dependent sRNAs including RyhB (De Lay and Gottesman 2011). RyhB is one of the best-characterized sRNAs in E. coli. Under iron replete conditions, RyhB expression is repressed by the iron bound form of the iron sensing transcriptional regulator protein Fur (ferric uptake regulator). Under iron limiting conditions Fur can no longer associate with free $\mathrm{Fe}^{2+}$ efficiently and consequently with DNA, which leads to RyhB expression. RyhB, in turn, acts to modulate iron homeostasis by down-regulating the expression of a large number of mRNAs encoding nonessential iron-containing proteins including sdhCDAB and sodB, which encode succinate dehydrogenase and superoxide dismutase, respectively (Massé and Gottesman 2002; Massé et al. 2003, 2005, 2007; Richards and Vanderpool 2011).

In the same genetic selection and screen that isolated $h f q$ and pnp mutants, independent point mutants were obtained in $p c n B$, the gene encoding poly(A) polymerase (PAP I), which were not investigated in detail (De Lay and Gottesman 2011). PAP I catalyzes polyadenylation of the $3^{\prime}$ extremities of RNA substrates and has a preference for Rho-independent transcription terminators containing 2$6 \mathrm{nt}$ single-stranded extensions (Mohanty and Kushner 2008, 2011, 2016; Régnier and Hajnsdorf 2013). Poly(A) tails promote transcript decay by providing toe-holds for $3^{\prime} \rightarrow 5^{\prime}$ exoribonucleases like RNase II, RNase R, and PNPase. PAP I interacts with $\mathrm{Hfq}$ and PNPase to form a polyadenylation complex. Hfq has been shown to stimulate polyadenylation of mRNAs by PAP I, most likely by binding to and recruiting PAP I to the $3^{\prime}$ ends of RNA substrates (Hajnsdorf and Régnier 2000; Le Derout et al. 2003; Mohanty et al. 2004).

PAP I adds poly(A) tails to many different classes of cellular RNAs (mRNAs, rRNAs, tRNAs, sRNAs, viral RNAs) (Régnier and Hajnsdorf 2013; Mohanty and Kushner
2016), and while the majority of E. coli ORFs undergo polyadenylation under exponential growth conditions, only a small fraction of them are polyadenylated at a specific time (Mohanty and Kushner 2006). Many sRNAs that do not require $\mathrm{Hfq}$ for stability and function have been shown to be polyadenylated in vivo, e.g., RNA I, Sok, Oop, SraL, SraG, and GImY, and are subsequently degraded by exoribonucleases (Régnier and Hajnsdorf 2013; Ruiz-Larrabeiti et al. 2016). Interestingly, previous data have shown that sRNAs that require $\mathrm{Hfq}$ for their stability, e.g., MicA and RybB, can also be targeted for degradation by PNPase and PAP I, but only when these sRNAs are not bound by Hfq (Andrade and Arraiano 2008; Andrade et al. 2012; Cameron and De Lay 2016).

In this study, we have further investigated the possible mechanisms by which the PAP I mediated polyadenylation led to a defect in sRNA function. Here, we report that deletion of $p c n B$ encoding PAP I resulted in a significant reduction in RyhB stability and consequently a defect in RyhBmediated repression of sdhCDAB and sodB transcripts. We provide evidence that the increased turnover of RyhB in a $p c n B$ deletion strain is due to increased accumulation of the $3^{\prime} E T S^{\text {LeuZ, }}$, which promotes more rapid RyhB degradation by RNase $E$ as a consequence of base-pairing interactions with this sRNA. Finally, we show that PAP I can stabilize another Hfq-dependent sRNA, MicA, but not others (GcvB, CyaR, ChiX, and MgrR), suggesting a specialized role of PAP I in conferring stability to a specific subset of Hfq-dependent sRNAs. This work provides further insight into how yet another protein previously known to be involved in initiating RNA decay contributes to sRNA-dependent gene regulation.

\section{RESULTS}

\section{Poly(A) polymerase stabilizes RyhB}

In a previous study (De Lay and Gottesman 2011), strains harboring null mutations in hfq, pnp, or pcnB encoding the RNA chaperone Hfq, the exoribonuclease PNPase, or the poly(A) polymerase PAP I, respectively, were recovered in a genetic selection and screen designed to isolate mutants defective for sRNA-mediated gene regulation. The selection was for mutations that allowed an E. coli $\Delta$ fur strain to grow on minimal succinate medium. In a fur deletion strain, RyhB is constitutively expressed and accumulates under the protection of $\mathrm{Hfq}$. In turn, Hfq promotes base-pairing with the sdhCDAB mRNA, blocking expression of succinate dehydrogenase complex and consequently leading to an inability of a fur mutant to grow on succinate as the sole carbon source (Massé and Gottesman 2002). Inactivation of pnp or hfq caused rapid turnover of RyhB leading to up-regulation of the sdhCDAB transcript, and consequently allowed a $\Delta$ fur 
stain to grow on succinate as the sole carbon source (De Lay and Gottesman 2011). Since the point mutations in $p c n B$ allowed growth on succinate minimal medium, we tested the effect of a pcnB deletion on RyhB stability. To test this, we first examined RyhB steady-state levels in exponentially growing cultures of $\Delta$ fur, $\Delta$ fur $\Delta p c n B$, and $\Delta$ fur $\Delta h f q$ strains. Introduction of a $p c n B$ deletion into the $\Delta$ fur strain resulted in a decrease in RyhB steady-state levels by $40 \%$ to $50 \%$ and were comparable to that in a $\Delta$ fur $\Delta h f q$ strain (Fig. $1 \mathrm{~A}, \mathrm{~B}$ ). As expected, RyhB was not detectable in a wild-type fur ${ }^{+}$strain (WT). Next, we determined RyhB stability in exponentially growing cultures of the aforementioned strains by blocking transcription initiation by adding rifampicin. RyhB levels were monitored by northern blot analysis of samples taken after transcription inhibition. RyhB was very stable in the $\Delta$ fur parent background under our experimental conditions, while introduction of an hfq deletion drastically reduced the stability of this sRNA (Table 1; Fig. 1C,D). Interestingly, introduction of a pcnB single deletion reduced RyhB stability significantly, but to a lesser extent than what was observed for an hfq mutant (Table 1; Fig. 1C,D).

Since deletion of pcnB led to increased turnover of RyhB, we decided to test whether PAP I was also required for the stability of other Hfq-dependent sRNAs including MicA, GcvB, CyaR, ChiX, and MgrR. We determined the stability of these sRNAs in exponentially growing cultures of a $\Delta p c n B$ and a wild-type strain as described above. Deletion of $p c n B$ led to $~ 50 \%$ reduction in MicA stability compared to the wild-type strain, while there were no significant differences in stability of GcvB, CyaR, ChiX, or MgrR between a wild-type and a $\Delta p c n B$ strain (Fig. 2; Supplemental Fig. S1). Overall, our data demonstrated that deletion of pcnB led to increased turnover of at least two Hfq-dependent sRNAs, RyhB and MicA.
A

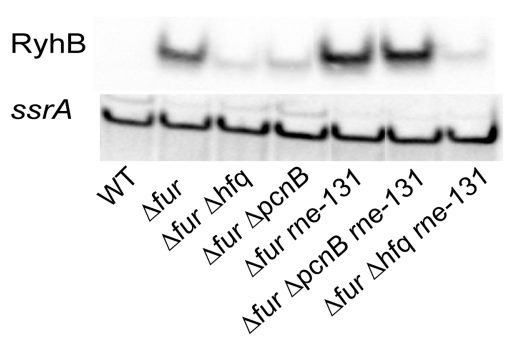

B

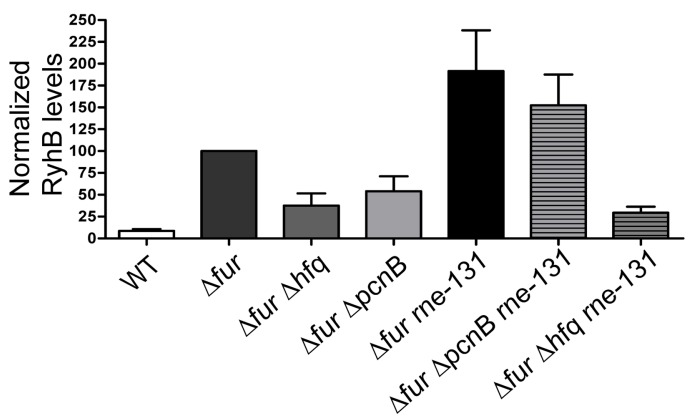

C

$\Delta$ fur

$\Delta$ fur $\Delta p c n B$

$\Delta$ fur $\Delta h f q$

$\Delta$ fur rne-131

$\Delta$ fur

rne-131 $\triangle p c n B$

$\Delta$ fur

rne-131 $\Delta h f q$

Min. after

Rif. addition
ssrA

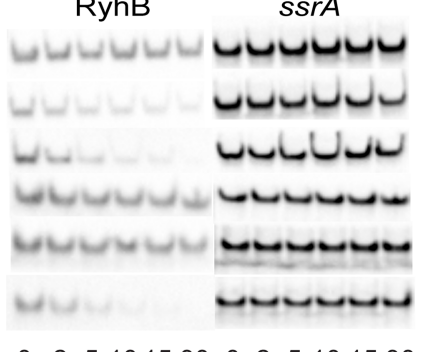

025101530025101530

D

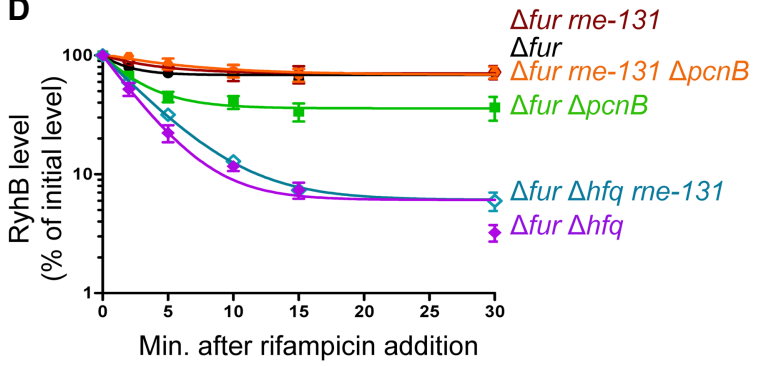

FIGURE 1. RyhB is rapidly degraded in the absence of poly(A) polymerase in an RNase E-dependent mechanism. $(A, B)$ Northern blot analysis to assess RyhB steady-state levels. Overnight cultures of strain NRD1138 (WT), an isogenic $\Delta$ fur strain (DS024), or derivatives of this $\Delta$ fur strain harboring deletions in hfq (DS027), pcnB (DS025), rne (DS069), rne and pcnB (DS082), and rne and hfq (DS153) were diluted 200-fold in fresh MOPS EZ rich defined media supplemented with $0.4 \%$ glycerol. All cultures were subsequently grown to late exponential phase $\left(O_{600}\right.$ of 1.0$)$, and samples were collected for RNA extraction. $(C, D)$ RNA stability time course experiment to determine the intrinsic stability of RyhB. Briefly, overnight cultures of the $\Delta$ fur parent (DS024) and its derived mutant strains ( $\Delta$ fur $\Delta p c n B, D S 025 ; \Delta$ fur $\Delta h f q$, DS027; $\Delta$ fur rne-131, DS069; $\Delta$ fur rne-131 $\Delta p c n B, D S 082 ; \Delta$ fur rne-131 $\Delta$ hfq, DS153) were grown to $\mathrm{OD}_{600}$ of 1.0 as described above and a culture sample was taken. Rifampicin was added to each culture to stop total transcription, and additional culture samples were taken 2, 5, 10, 15, and 30 min after rifampicin addition. All samples were subjected to RNA extraction and were prepared for northern blot analysis as described in Materials and Methods. Representative northern blots are shown in $A$ and $C$. $(B, D)$ RyhB signal intensities in the northern blots were quantified and normalized to their corresponding loading controls (ssrA). sRNA decay curves were generated by fitting the normalized signal intensities for each time point. Points and error bars in the curves represent the means and the standard errors (SEM) of at least three independent experiments. RyhB half-life measurements corresponding to RNA stability curves $(D)$ are listed in Table 1. 
TABLE 1. RyhB half-life measurements in various $E$. coli mutant strains

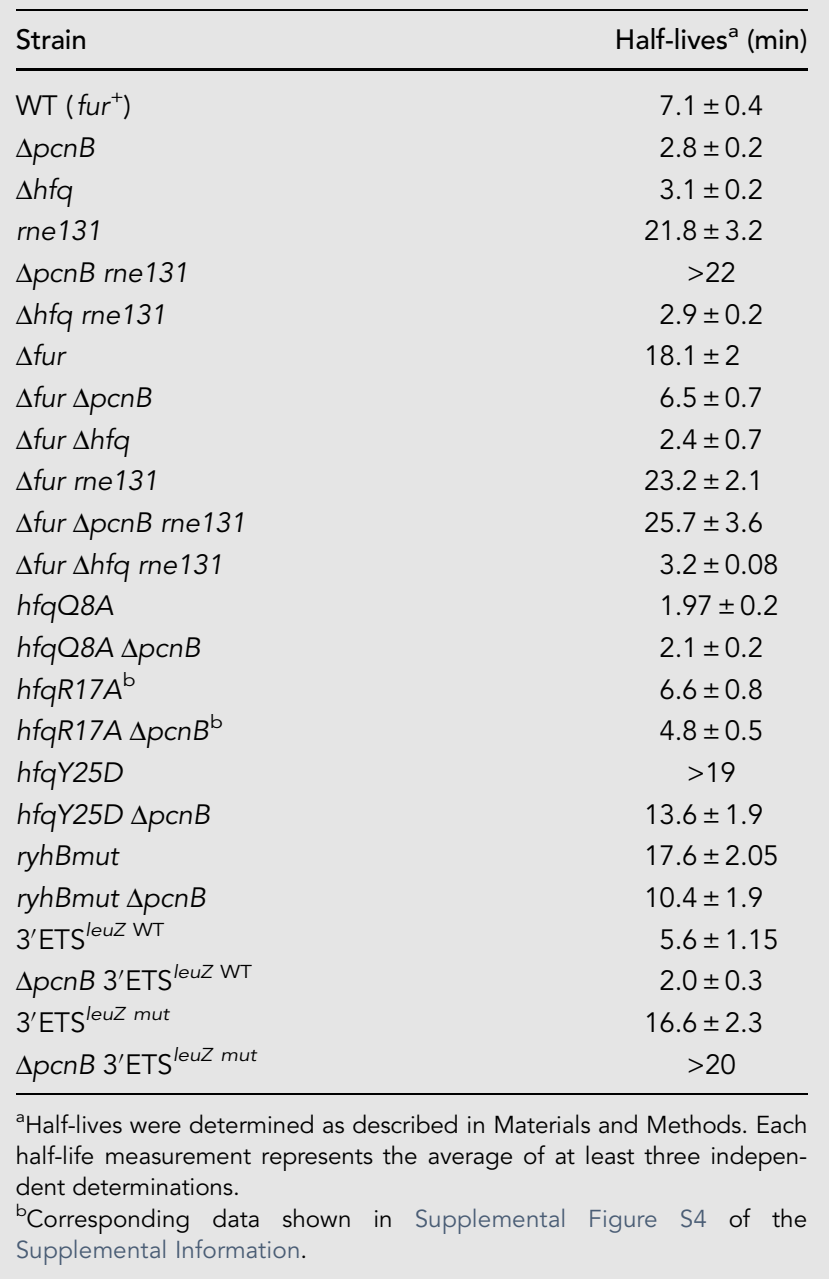

\section{Poly(A) polymerase is important for RyhB-mediated target gene regulation}

Based on the results reported above, we investigated whether this defect in RyhB stability in a pcnB deletion mutant led to a subsequent defect in RyhB-dependent target gene regulation. To test this idea, we focused on the two well-characterized RyhB target mRNAs, sodB and sdhCDAB. We determined the relative levels of sodB using northern blotting and sdhCDAB by qRT-PCR using specific primers to probe for transcripts containing $s d h C$ and $s d h D$ in exponential phase cultures of a $\Delta$ fur strain or derived strain harboring a deletion in $p c n B(\Delta p c n B)$ in the presence (+ryhB) or absence $(\Delta r y h B)$ of ryhB. We observed a greater than fivefold down-regulation of $\operatorname{sod} B$ transcript levels by RyhB in the $\Delta$ fur strain (Fig. $3 A, B$; compare $\Delta$ fur versus $\Delta$ fur $\Delta r y h B)$. However, in the corresponding isogenic $\Delta p c n B$ strains, RyhB-dependent regulation of $\operatorname{sod} B$ was only 2.2-fold (Fig. $3 A, B$; compare $\Delta$ fur $\Delta p c n B$ versus $\Delta$ fur $\Delta p c n B \Delta r y h B)$. Furthermore, we found that $\operatorname{sod} B$ was turned over less rapidly in a $\Delta p c n B$ mutant $\left(t_{1 / 2}=4.7 \mathrm{~min}\right)$ relative to a wild-type $\left(t_{1 / 2}=3.4 \mathrm{~min}\right)$ strain upon $\mathrm{RyhB}$ induction (Supplemental Fig. S2). The decreased rate of $\operatorname{sod} B$ target degradation in a $p c n B$ mutant indicated a defect in RyhB-mediated sodB repression. Similarly, qRTPCR analysis showed a nearly threefold down-regulation of sdhC transcript levels by RyhB in a $\Delta$ fur strain background (Fig. $3 C$; compare $\Delta$ fur versus $\Delta$ fur $\Delta r y h B$ ), whereas in the $\Delta$ fur $\Delta p c n B$ strain RyhB expression caused only a 1.7fold reduction in sdhC levels (Fig. 3C; compare $\Delta$ fur $\Delta p c n B$ versus $\Delta$ fur $\Delta p c n B \quad \Delta r y h B$ ). These results suggested a defect in RyhB-mediated regulation of sdhCDAB in the absence of PAP I. Interestingly, sdhC transcript levels were higher in a $\Delta$ fur $\Delta p c n B \Delta r y h B$ strain than in the $\Delta$ fur $\Delta r y h B$ strain (Fig. 3C), suggesting that PAP I-mediated sdhCDAB regulation was both RyhB-dependent and RyhB-independent. Similar results were also obtained when we probed the sdhCDAB transcript by qRT-PCR using primers specific for sdhD instead of sdhC (Supplemental Fig. S3); i.e., introduction of the $p c n B$ deletion into a $\Delta$ fur parent background up-regulated $s d h D$ steady-state levels by threefold (Supplemental Fig. S3). Altogether, our results indicated that deletion of $p c n B$ resulted in increased $\operatorname{sod} B$ transcript levels as a consequence of reduced RyhB levels, whereas the higher levels of sdhCDAB mRNA in the absence of PAP I were likely due to reduced RyhB levels and loss of PAP I-mediated regulation of the sdhCDAB transcript that was RyhB-independent.

Finally, we investigated whether PAP I can similarly impact MicA-mediated target gene regulation. To test this, we determined steady-state levels of two MicA-targets ompA and ompX, which encode outer membrane proteins, in a pcnB deletion and wild-type strain under conditions where MicA expression was induced or uninduced. We observed a 4.2-fold and 2.6-fold down-regulation of ompA and ompX transcript levels, respectively, by MicA in the wild-type strain while in the corresponding isogenic $\triangle p c n B$ strain, there was only a modest loss in MicA-dependent regulation of ompA (3.3-fold) and ompX (2.2-fold) (Supplemental Fig. S4). Taken together, our data indicated that PAP I plays a crucial role in promoting stability and function of RyhB and MicA.

\section{Hfq mediates accelerated decay of RyhB in the absence of poly(A) polymerase}

Based on our observations, we next investigated the mechanism by which PAP I promoted sRNA stability by focusing on RyhB. Since Hfq was essential for RyhB stability, we first determined whether PAP I impacted Hfq protein levels. Hfq protein levels were comparable between a wild-type and $p c n B$ deletion strain under exponential growth conditions, indicating that the decreased stability of RyhB in a pcnB mutant strain was not due to lower levels of Hfq (Fig. 4A,B). Results from previous studies indicated that 
A

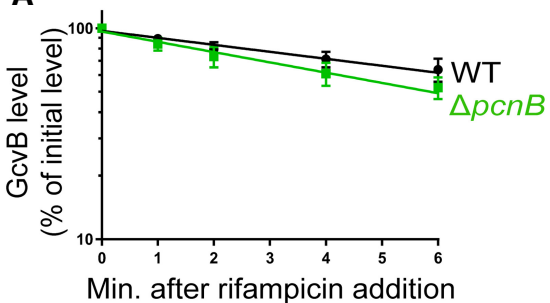

C

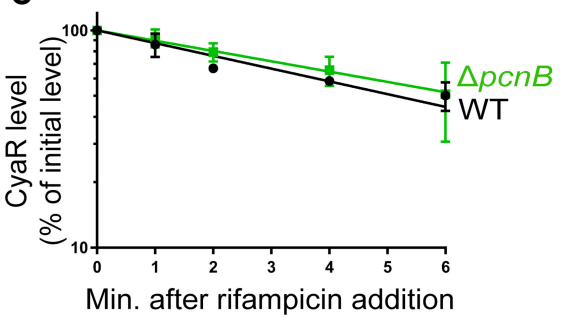

E

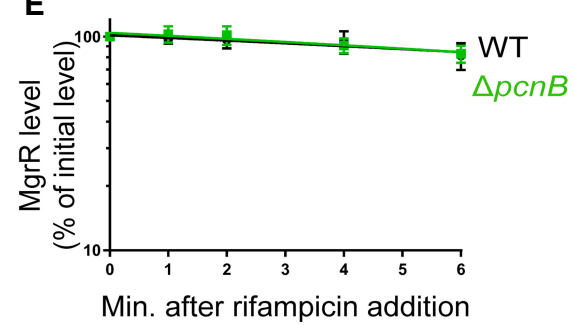

FIGURE 2. A subset of Hfq-dependent sRNAs are unstable in the absence of poly(A) polymerase. RNA stability time-course experiments to determine the intrinsic stabilities of $\operatorname{GcvB}(A)$, MicA $(B)$, CyaR $(C)$, ChiX $(D)$, and MgrR (E) sRNAs. $(A, B)$ Strain TC279 $\left(W T\right.$; fur $\left.{ }^{+}\right)$, which has MicA under the control of the ryhB promoter, and an isogenic $\Delta p c n B$ strain $(\Delta p c n B, D S 120)$ were grown to exponential phase. Dipyridyl was added to each culture for $15 \mathrm{~min}$ to induce MicA expression, a sample was taken, rifampicin was added to block transcription, and additional samples were taken 1, 2, 4, and 6 min after rifampicin addition. RNA was extracted and northern blot analysis was performed probing for MicA or GcvB as described in Materials and Methods. To determine intrinsic stabilities of CyaR $(C), \operatorname{ChiX}(D)$, and MgrR $(E)$, the wild-type strain (NRD1138) and its derived pcnB mutant (NRD1198) were grown to exponential phase, CyaR was induced from its native promoter by cAMP addition, a sample was taken after 15 min of induction, rifampicin was then added, and additional samples were taken 1, 2, 4, and 6 min after transcription inhibition. Northern blot analysis was performed using RNA extracted from these samples probing for CyaR, ChiX, and MgrR. Representative northern blots for each sRNA are shown in Supplemental Figure S1 (Supplemental Information). For the decay curves, sRNA signal intensities from the northern blots were quantified and normalized to their corresponding loading controls (ssrA or 5S). Points and error bars in the curves represent the means and the standard errors (SEM) of at least three independent experiments. ference was observed in the amount of RyhB that coimmunoprecipitated with $\mathrm{Hfq}$ between the wild-type and $\Delta$ pcnB strain (Fig. 4C,D). Altogether, our results indicated that PAP I did not facilitate RyhB binding to $\mathrm{Hfq}$ in vivo.

Recent studies directed toward understanding Hfq-RNA interactions have led to the identification of four distinct surfaces on $\mathrm{Hfq}$ : the proximal face, distal face, rim, and the C-terminal tail, each possessing unique structural characteristics which promote binding of different RNAs in particular configurations (Vogel and Luisi 2011; Zhang et al. 2013; Schu et al. 2015; Updegrove et al. 2016). sRNAs are classified into two distinct classes, Class I and Class II, based on their mode of $\mathrm{Hfq}$ binding. RyhB is a Class I Hfq-binding sRNA shown to bind to sites on the Hfq proximal face via the poly(U) tail of its Rho-independent terminator and the rim via its UA-rich sequence, while RyhB target mRNAs typically interact with the Hfq distal face via repeats of an ARN sequence motif (Fig. 4E). Binding studies with several $\mathrm{Hfq}$ mutants have demonstrated that specific conserved residues on the proximal face (08, F42, K56) and rim (R16, R17, R19) were important for binding of Class I sRNAs to $\mathrm{Hfq}$, and substitutions in these residues negatively impacted sRNA steadystate levels and stability. On the other hand, specific residues on the Hfq distal face (Y25, 130) were important for cognate mRNA target binding, and substitutions in these residues stabilized Class I sRNAs by protecting them from the subsequent degradation following sRNA-mRNA pairing mediated by Hfq (Zhang et al. 2013;

PAP I together with $\mathrm{Hfq}$ mediates efficient polyadenylation at the $3^{\prime}$ ends of Rho-independent terminators which subsequently facilitates $\mathrm{Hfq}$ binding to those mRNAs (Hajnsdorf and Régnier 2000; Mohanty and Kushner 2008, 2016; Mohanty et al. 2004; Régnier and Hajnsdorf 2013). We extended this idea to sRNAs and thus tested whether PAP I stabilized RyhB by increasing its binding to $\mathrm{Hfq}$. We compared the total amount of RyhB to the amount immunoprecipitated with $\mathrm{Hfq}$ from cell lysates of a wild-type or an isogenic $\Delta p c n B$ strain; no significant dif-
Schu et al. 2015; Updegrove et al. 2016).

Our results so far indicated that PAP I did not impact RyhB binding to $\mathrm{Hfq}$, but at the same time was required to stabilize RyhB in vivo. This observation prompted us to determine whether PAP I was contributing to RyhB stability by impacting the interaction of RyhB target RNAs with $\mathrm{Hfq}$. To test this possibility, we introduced different $h f q$ point mutations (hfqQ8A [proximal face], $h f q R 17 A$ [rim], and $h f q Y 25 D$ [distal face]) into a wild-type or a $\Delta p c n B$ mutant strain and monitored RyhB stability 
as described above (Fig. 4E,F; Supplemental Fig. S5). Introduction of the $h f q Y 25 D$ mutation not only suppressed the defect in RyhB stability observed for a $\triangle p c n B$ mutant $\left(t_{1 / 2}=2.8 \mathrm{~min}\right.$ for a $\Delta p c n B$ strain versus $t_{1 / 2}=13.6 \mathrm{~min}$ for the $\Delta p c n B$ hfqY25D strain) but further led to a significant increase in the stability of this sRNA compared to the wild-type strain ( $\left.t_{1 / 2}=7.1 \mathrm{~min}\right)$. RyhB stabilities were comparable between an $h f q Y 25 D$ single and a $\Delta p c n B$ hfqY $25 D$ double mutant strain (Fig. 4F). In contrast, introduction of the $h f q Q 8 A$ mutation into the $\triangle p c n B$ strain did not suppress the defect in RyhB stability, and RyhB was rapidly degraded in either an $h f q Q 8 A$ mutant $\left(t_{1 / 2}=1.97 \mathrm{~min}\right)$ or a $\triangle p c n B$ hfqQ8A double mutant $\left(t_{1 / 2}=2.1 \mathrm{~min}\right)$ as compared to a wild-type strain $\left(t_{1 / 2}=7.1 \mathrm{~min}\right)$ (Table 1 ; Fig. $\left.4 \mathrm{~F}\right)$. This result was consistent with previous studies showing that an alanine substitution in the $\mathrm{Hfq}$ proximal face residue Q8 disrupted $\mathrm{Hfq}$ binding to RyhB leading to the rapid degradation of this sRNA (Zhang et al. 2013; Schu et al.

A

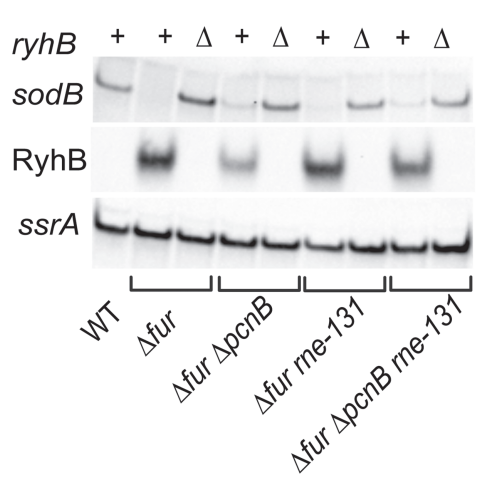

B
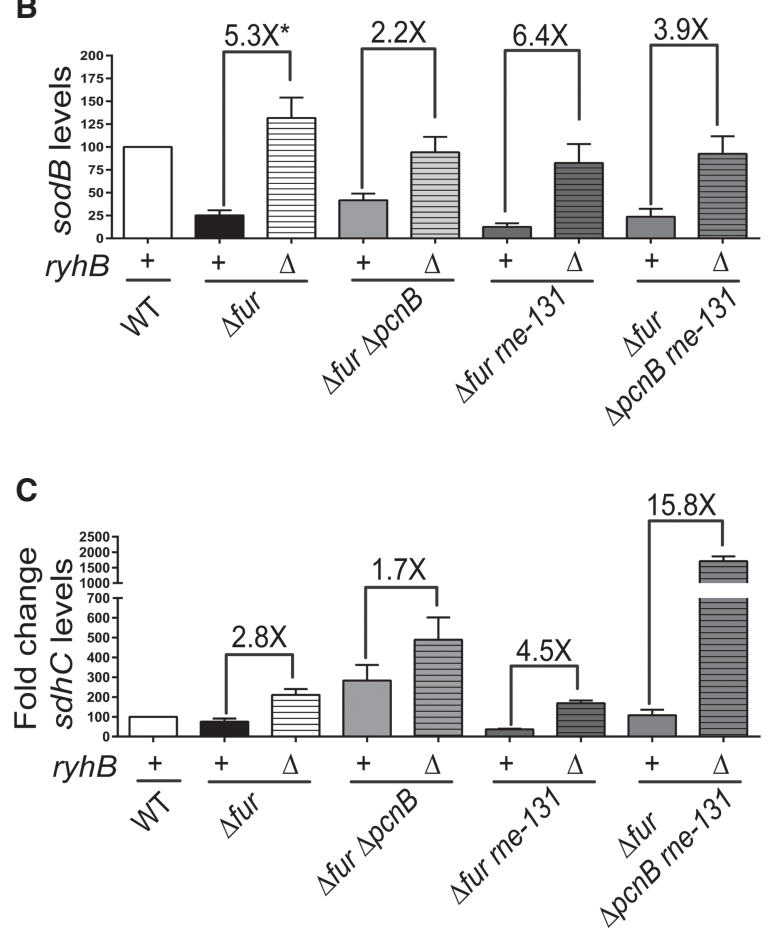

2015). Finally, introduction of the hfqR17A mutation into a wild-type or a $\triangle p c n B$ strain background did not significantly decrease RyhB stability relative to that observed in the wild-type strain (Table 1; Supplemental Fig. S5). These data were in agreement with previous studies showing that mutations in the rim-binding residues were not sufficient to lead to a defect in RyhB function (Schu et al. 2015). Overall our data indicated that residue Y25 located on the distal face of $\mathrm{Hfq}$ and known to be important for binding targets of RyhB was essential for the decay of RyhB in the absence of PAP I.

\section{Poly(A) polymerase protects RyhB from target pairing mediated decay}

RyhB was previously shown to be degraded along with its target RNAs upon sRNA-mRNA pairing (Massé et al. 2003; Lalaouna et al. 2015b). Furthermore, the Y25D substitution in $\mathrm{Hfq}$ has been shown to reduce the ability of RyhB to regulate target mRNAs by disrupting Hfq-target RNA interactions (Schu et al. 2015). Thus, based on our results demonstrating the ability of an $\mathrm{Hfq}^{\text {Y25D }}$ variant to suppress the defect in RyhB stability observed in a $\triangle p c n B$ strain, we hypothesized that RyhB instability in a $\triangle p c n B$ strain was a consequence of pairing with target RNAs. To explore this possibility, we constructed a RyhB pairing mutant (ryhBmut) in which bases $\mathrm{G}$ and $\mathrm{C}$ at positions 44 and 45 were inverted (Fig. 5A). These mutations were previously shown to abolish the ability of RyhB to repress the translation of the open reading frame upstream of fur (uof) and fur

FIGURE 3. In the absence of poly(A) polymerase, RyhB does not efficiently regulate $\operatorname{sod} B$ and $s d h C D A B$ target mRNAs. $(A, B)$ Northern blot analysis was used to determine RyhB and $\operatorname{sod} B$ steady state in the wild-type and derived isogenic mutant strains, and (C) qRT-PCR analysis was used to determine sdhC levels. Wild-type parent (WT $\left[\right.$ fur ${ }^{+}$; NRD1138) and its derived isogenic mutants ( $\triangle$ fur, DS024; $\Delta$ fur $\Delta p c n B$, DS025; $\Delta$ fur rne-131, DS069; $\Delta$ fur $\Delta p c n B$ rne-131, DS082; $\Delta$ fur $\Delta r y h B, N R D 1546 ; \Delta$ fur $\Delta$ pcnB $\Delta r y h B, N R D 1547 ; \Delta$ fur rne-131 $\Delta r y h B$, NRD1550; $\Delta$ fur $\Delta p c n B$ rne-131 $\Delta r y h B$, NRD1551) were diluted 200 -fold in fresh MOPS EZ rich defined media supplemented with $0.4 \%$ glycerol and grown to late exponential phase $\left(O D_{600}\right.$ of 1.0), and samples for RNA extraction were collected. Representative northern blots are shown $(A)$. $(B, C)$ Graphs are presented that display the relative expression levels of sodB and sdhC mRNA in a wild-type strain and derived mutant strains. Briefly, the signal intensities for $s o d B$ and $s d h C$ transcripts were first quantified from northern blots or qRT-PCRs. The signal intensity was then normalized to the ssrA transcript level, which served as the loading control, and subsequently the expression level relative to the fur ${ }^{+}$(WT) strain NRD1138, which was set at $100 \%$, was calculated. sdhC transcript fold changes relative to NRD1138 were calculated via the $\Delta \Delta C_{t}$ method. Asterisk $(*)$ in $B$ indicates that the calculated fold change is $>5.3 \times$ since sodB steady-state determination in DS024 ( $\Delta$ fur) strain was not accurate due to very low signal intensity. Data shown in $B$ and $C$ represent the mean $( \pm$ SEM) of at least three independent experiments. Probes and primers used are listed in Supplemental Table S2. 
A

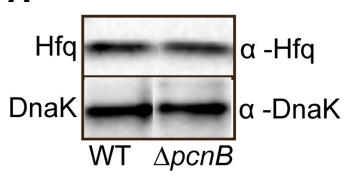

B

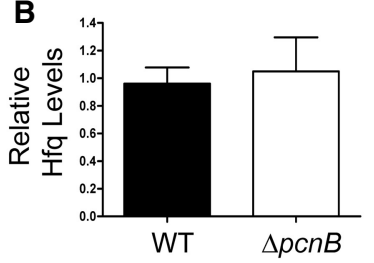

C

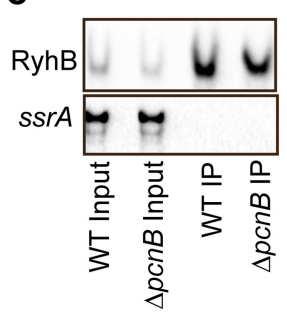

D

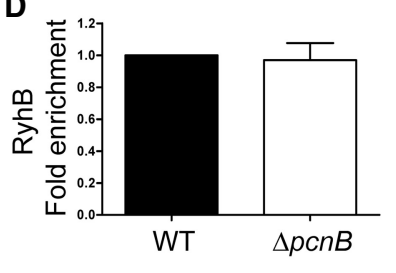

E

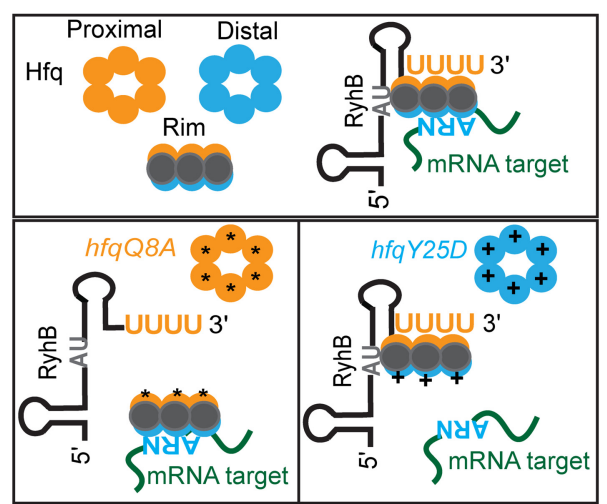

$\mathbf{F}$

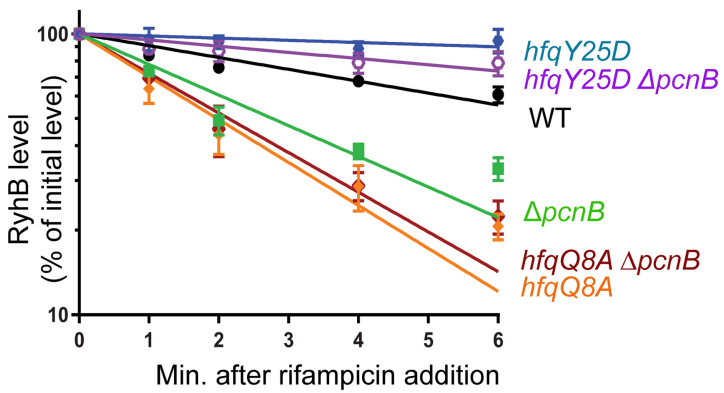

FIGURE 4. The accelerated decay of RyhB in the absence of poly $(A)$ polymerase is mediated by $H f q .(A, B)$ Western blot analysis to determine Hfq protein levels. Samples were prepared for western blotting from exponential phase cultures of a fur ${ }^{+}$strain (DS090), and its derived strain $\Delta p c n B$ (DS092) with anti-Hfq antibody. Protein band intensities were normalized to DnaK detected with an anti-DnaK antibody (Materials and Methods). Representative western blots are shown in A. Quantification of Hfq levels from those western blots normalized to DnaK levels are shown in $B$. $(C, D)$ Coimmunoprecipitation of RyhB with Hfq. RyhB expression was induced in exponential cultures of a wild-type (NRD1138) and an isogenic $\Delta p c n B$ mutant (NRD1198). Hfq was immunoprecipitated with anti-Hfq antibody bound to protein-A-sepharose. RNA extracted from the input and elution fractions were loaded in 1:8 ratio, and RyhB and ssrA levels were determined via northern blot analysis (C). Fold enrichment of RyhB (D) was determined after quantification of the RyhB and ssrA signal intensities in those northern blots as described in Materials and Methods. (E) Schematic showing interactions between RyhB, mRNA targets, and Hfq based on work by Schu and coworkers (Zhang et al. 2013; Schu et al. 2015); a Q8A substitution in the proximal face of Hfq was shown to disrupt RyhB binding, whereas a Y25D substitution in the distal face of $\mathrm{Hfq}$ reduced binding of RyhB target mRNAs such as sodB. $(F)$ RNA half-life experiments to determine RyhB stability in the wild-type strain and its derived isogenic $h f q$ and $p c n B$ mutants. Overnight cultures of the wild-type strain (WT [fur ${ }^{+}$; NRD1138) and its derived mutants $(\Delta p c n B, N R D 1198 ;$ hfqQ8A, DS060; hfqY25D, NRD1410; hfqQ8A $\Delta p c n B$, DS072; hfqY25D $\Delta p c n B, D S 185)$ were diluted 200-fold in fresh LB media. Cultures were subsequently grown to exponential phase, dipyridyl was added to induce RyhB expression, and a culture sample was taken after $15 \mathrm{~min}$ of induction. Rifampicin was added to each culture to stop total transcription, and additional culture samples were taken 1, 2, 4, and $6 \mathrm{~min}$ after rifampicin addition. RNA extraction and northern blot analysis were performed as described above. Representative northern blots are shown in Supplemental Figure S5 of Supplemental Information. For decay curves, RyhB signal intensities from the northern blots were quantified and normalized to their corresponding loading controls (SsrA). Data shown in $B, D$, and Frepresent the means and the standard errors (SEM) of at least three independent experiments. RyhB half-life measurements corresponding to RNA stability curves are listed in Table 1.

(Vecerek et al. 2007). Moreover, these nucleotides in RyhB are located in its seed sequence involved in pairing with other targets including sdhCDAB and sodB mRNAs (Fig. 5A; Massé and Gottesman 2002; Desnoyers and Massé 2012; Peterman et al. 2014; Waters et al. 2017). We assessed whether introducing these mutations into ryhB could suppress the defect in RyhB stability observed in a $\Delta p c n B$ strain by monitoring RyhB or RyhBmut steady-state levels in exponential phase cultures of $\Delta p c n B$ and $p c n B^{+}$ strains by northern blot analysis. Interestingly, introduction of the G44C C45G mutations into ryhB in a $\Delta p c n B$ mutant background suppressed the defect in RyhB levels. Furthermore, RyhB levels increased by approximately 1.5- and twofold in a $\triangle p c n B$ ryhBmut double mutant and a ryhBmut single mutant, respectively, compared to the wild-type strain (Fig. 5B,C). Next, we tested whether the increased levels of RyhB in the $\triangle p c n B$ ryhBmut strain compared to the $\triangle p c n B$ ryhB ${ }^{+}$strain were due to increased stability of the sRNA by monitoring RyhB turnover in exponential phase cultures of these strains after transcription inhibition. As shown in Figure 5D,E and Table 1, the RyhB stability defect observed in a $\triangle p c n B$ mutant was completely suppressed by introduction of these mutations in the pairing region of RyhB.

In parallel, we tested whether RyhBmut was defective in regulating the sodB and furmRNAs. Northern blot analysis showed that in the wild-type strain sodB mRNA levels were much lower under RyhB inducing conditions (+dipyridyl) 


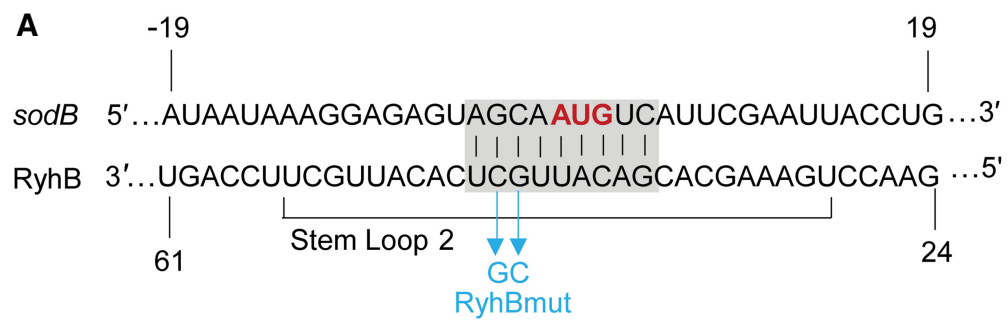

B

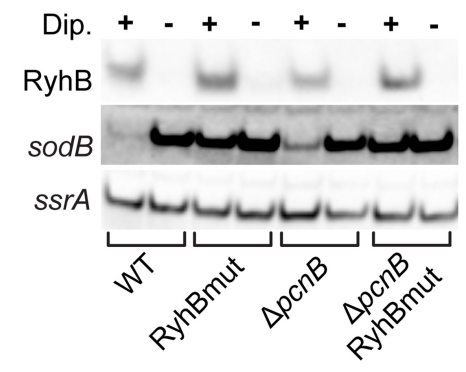

D

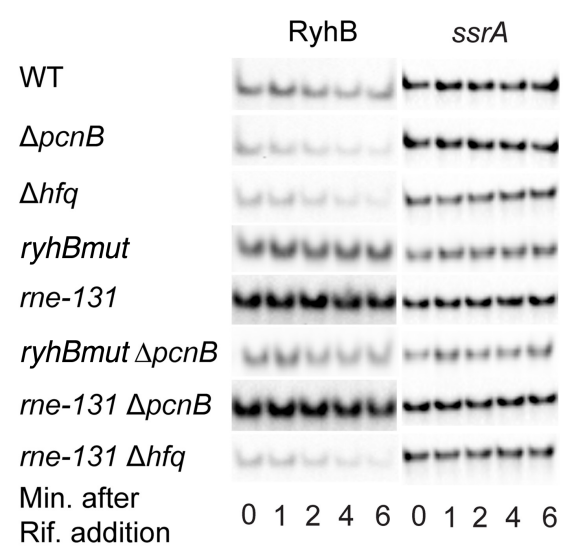

C

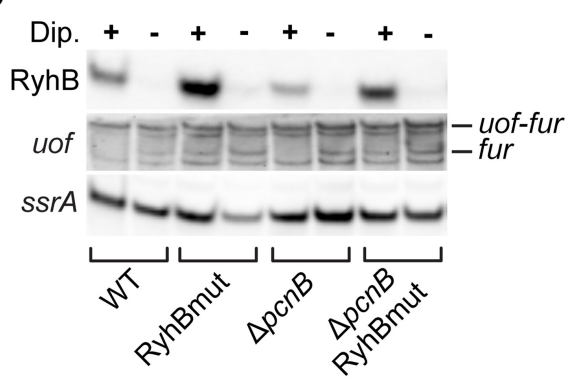

E

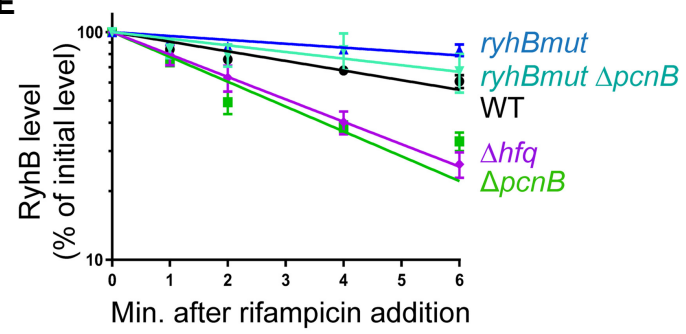

$\mathbf{F}$

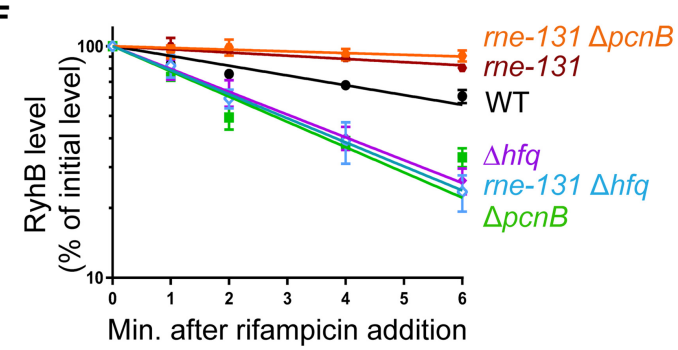

FIGURE 5. The instability of RyhB in the absence of poly(A) polymerase is due to pairing with target RNAs. (A) Schematic showing complementarity (highlighted in gray) between RyhB and its target mRNA sodB, and the specific mutations (in cyan) introduced in RyhB to create a RyhB variant unable to pair with target mRNAs (RyhBmut). The start codon of $\operatorname{sod} B$ is highlighted in red. $(B, C)$ Northern blot analysis to determine the transcript steady-state levels of RyhB targets sodB and uof in a wild-type strain (WT [ fur ${ }^{+}$; NRD1138) and its derived isogenic mutants $(\Delta p c n B$, NRD1198; ryhBmut, LM11; ryhBmut $\Delta p c n B$ ) under RyhB inducing and noninducing conditions. Overnight cultures of these strains grown in LB were diluted 200-fold in fresh LB media and grown to log phase and treated with dipyridyl (+) to chelate iron or mock-treated (-). After 15 min of treatment, RNA was extracted from each culture and prepared for northern blot analysis to determine corresponding levels of sodB, uof, RyhB, and ssrA (loading control). uof transcription is driven from two upstream promoters $P_{\text {uof }}$ and $P_{\text {fur }}$ to generate the uof-fur and fur mRNAs, respectively, but RyhB specifically interacts with the fur mRNA $(C)$. (D-F) Determination of RyhB intrinsic stability in a wild-type (WT [fur ${ }^{+}$; NRD1138) and its derived isogenic mutants $(\Delta p c n B, N R D 1198 ; \Delta h f q, D S 021 ;$ ryhBmut, LM11; ryhBmut $\Delta p c n B$, LM13; rne-131, DS102; rne$131 \Delta p c n B, D S 106 ;$ rne-131 $\Delta \mathrm{hfq}, \mathrm{DS} 130$ ). Strains were subjected to RNA stability time-course experiments as described in the legend of Figure 4. Representative northern blots are shown in $D$. $(E, F)$ RyhB decay curves were generated as described in Figure 4 and corresponding half-life measurements are listed in Table 1. Points and error bars in the curves represent the means and the standard errors (SEM) of at least three independent experiments.

than under noninducing conditions (-dipyridyl) in line with its role in negatively regulating the sodB mRNA (Fig. 5B). Consistent with our previous observations, introduction of a $p c n B$ deletion in the wild-type background led to a subsequent defect in RyhB-dependent sodB regulation as indicated by an increased accumulation of $\operatorname{sod} B$ transcript under RyhB inducing conditions in a $\triangle p c n B$ mutant relative to the wild-type strain (Fig. 5B; Supplemental Fig. S6). In contrast, sodB mRNA levels were comparable in a ryhBmut mutant and a ryhBmut $\Delta p c n B$ double mutant 
strains under both inducing and noninducing conditions consistent with $\mathrm{G} 44$ and $\mathrm{C} 45$ of RyhB being critical for sRNA-mRNA pairing. Additionally, we found that the fur mRNA, transcribed from the $P_{\text {fur }}$ promoter located within the uof ORF was down-regulated upon RyhB induction in both the wild-type and $\triangle p c n B$ strains whereas the level of this transcript was unaffected by RyhBmut expression in ryhBmut and ryhBmut $\Delta$ pcnB mutant strains (Fig. $5 C$ ). Interestingly, RyhB was not able to facilitate the decay of the uof-fur mRNA transcribed from the $\mathrm{P}_{\text {uof }}$ promoter located upstream of uof ORF, even though RyhB negatively regulated fur mRNA levels by interacting with the same site. This finding further suggested that the context of RyhB pairing was important for its interaction with certain target transcripts. Taken together our results confirmed that the G44C C45G mutations in RyhBmut block pairing with at least some target mRNAs, indicating that the rapid turnover of RyhB in the absence of PAP I was dependent upon pairing with target RNAs.

\section{The C-terminal domain of RNase $E$ is required for RyhB degradation in the absence of $\operatorname{poly}(A)$ polymerase}

The C-terminal domain (CTD) of RNase E plays an important role in coupled degradation of RyhB and its target mRNAs following $\mathrm{Hfq}$-mediated pairing, and previous studies have demonstrated that this pairing mediated decay can be suppressed by introduction of an internal deletion in rne (rne-131) (Massé et al. 2003; Prévost et al. 2011; Desnoyers and Massé 2012). This mutation (rne-131) leads to production of an RNase E lacking the CTD. The CTD contains two RNA binding regions, ARRBD (or AR1) and $A R 2$, but also interacts with other proteins including enolase, the RNA helicase RhIB, and PNPase to form the RNA degradosome, the central RNA degradation machine (Vanzo et al. 1998; Callaghan et al. 2004; Morita et al. 2005). To further test this hypothesis that absence of PAP I resulted in accelerated decay of RyhB due to increased target pairing, we assessed the ability of an rne-131 mutant to suppress the defect in RyhB stability in the $\Delta p c n B$ strain. Introduction of the rne-131 mutation suppressed the defect in RyhB stability caused by the pcnB deletion in both the fur ${ }^{+}$(Table $1 ;$ Fig. 5D,F) and $\Delta$ fur background (Table 1; Fig. 1C,D) leading to a significant increase in RyhB stability in both strains. Additionally, RyhB steadystate levels were up-regulated by 1.9- and 1.5-fold in $\Delta$ fur rne-131 and $\Delta$ fur $\Delta p c n B$ rne-131 mutants, respectively relative to the $\Delta$ fur strain (Fig. $1 \mathrm{~A}, \mathrm{~B}$ ). Interestingly, the rne131 mutation failed to suppress the RyhB stability defect in a $\Delta h f q$ (Table 1 ; Fig. 5D,F) or a $\Delta$ fur $\Delta h f q$ strain background (Table 1; Fig. 1C,D), indicating that the CTD of RNase $E$ was not critical for the degradation of sRNAs not associated with $\mathrm{Hfq}$.
Since introduction of the rne-131 mutation into the $\Delta$ fur $\Delta p c n B$ strain suppressed the defect in RyhB stability, we examined whether this mutation also suppressed the defect in regulation of $s o d B$ and $s d h C D A B$ mRNAs by RyhB. As shown in Figure $3 \mathrm{~B}$, we found that introduction of the rne131 allele had a modest ability to suppress the defect in RyhB-mediated regulation of sodB in the $\Delta p c n B$ strain (compare 2.2-fold repression in the $\Delta$ fur $\Delta p c n B$ strain to 3.9-fold in the $\Delta$ fur $\Delta p c n B$ rne-131 strain). The ability of the rne-131 mutation to suppress the defect in RyhB-mediated regulation of the solhCDAB transcript was demonstrated by a 15.8-fold decrease in sdhC in the $\Delta$ fur $\Delta$ pcnB rne-131 strain relative to the $\Delta$ fur $\Delta p c n B$ rne-131 $\Delta r y h B$ strain. In contrast, sdhC levels were 1.7-fold lower in the $\Delta$ fur $\Delta p c n B$ strain relative to the $\Delta$ fur $\Delta p c n B \Delta r y h B$ strain (Fig. $3 C$ ).

Finally, we examined whether the defect in the ability of RyhB to regulate sdhCDAB mRNA in the $\triangle$ fur $\triangle p c n B$ strain relative to the $\Delta$ fur parental strain had any impact on its ability to grow on succinate as a sole carbon source. As mentioned above, it has been demonstrated that a $\Delta$ fur mutant is unable to grow on succinate minimal medium due to constitutive RyhB repression of the sdhCDAB transcript. As expected, deletion of $h f q$ in a $\Delta$ fur background allowed growth on succinate minimal medium with a yield similar to that observed for a wild-type $\left(\right.$ fur $\left.{ }^{+}\right)$strain at the end of $24 \mathrm{~h}$ and $48 \mathrm{~h}$ of growth (Supplemental Fig. S7). Although the growth yields between the $\Delta$ fur $\Delta p c n B$ and the $\Delta$ fur $\Delta h f q$ strains differed significantly at the end of $24 \mathrm{~h}$, the pcnB deletion strain nonetheless reached growth yields comparable to that of an $\mathrm{hfq}$ deletion strain after 48 h (Supplemental Fig. S7). Consistently, the rne-131 mutation suppressed the succinate growth phenotype observed for a $\Delta$ fur $\Delta p c n B$ strain as indicated by a failure of the $\Delta$ fur $\Delta p c n B$ rne-131 triple mutant to grow on succinate minimal medium (Supplemental Fig. S7).

\section{Increased levels of $3^{\prime}$ ETS ${ }^{\text {LeuZ }}$ drive RyhB decay in the absence of poly(A) polymerase}

Based on our findings, we hypothesized that PAP I facilitates the decay of a certain pool of RyhB target RNAs, which otherwise accumulate in the absence of PAP I, pair with RyhB, and drive its degradation via an RNase E-dependent decay pathway. Recent RNA-seq studies (Maes et al. 2017) identified a potential list of RNAs that serve as substrates for polyadenylation in E. coli. One of RyhB targets, the LeuZ precursor tRNA encoded by leuZ, was shown to be upregulated in a $\triangle p c n B$ mutant (Maes et al. 2017) and to be polyadenylated downstream from the Rho-independent transcription terminator present at the end of its $3^{\prime}$ external transcribed spacer (3'ETS ${ }^{\text {LeuZ) }}$ (Li and Deutscher 2002; Ow and Kushner 2002). Furthermore, recent studies also demonstrated that overexpression of $3^{\prime}$ ETS $^{\text {LeuZ }}$ results in reduced levels of RyhB via pairing mediated decay (Lalaouna et al. 2015a,b). Based on these data, we first 

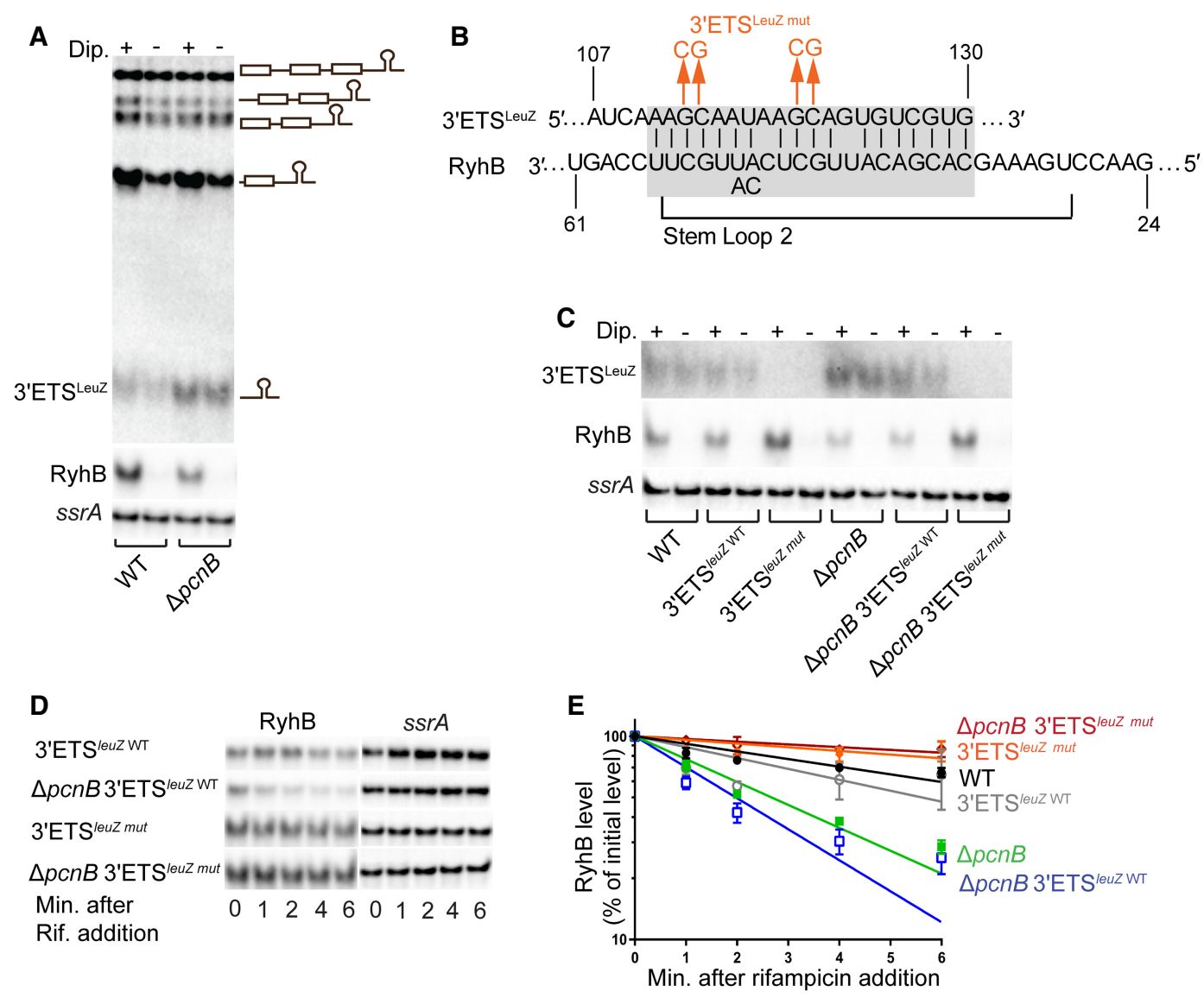

FIGURE 6. $3^{\prime}$ ETS LeuZ drives RyhB decay in the absence of poly(A) polymerase. $(A)$ Northern blot analysis to determine the steady-state levels of $3^{\prime}$ ETS ${ }^{\text {LeuZ }}$ and RyhB in a wild-type (WT [ fur ${ }^{+}$]; NRD1138) and the derived $\triangle p c n B$ strain (NRD1198) under RyhB inducing and noninducing conditions. Experiments were performed as described in the legend of Figure 5B,C. The primary glyW-cystT-leuZ transcript and the derived processing products that were detected in the northern blot are shown to the right of blot image. (B) Schematic showing complementarity (highlighted in gray) between RyhB and its target $3^{\prime} E T S^{\text {LeuZ }}$, and the specific mutations (in orange) introduced in $3^{\prime} E T S^{\text {LeuZ }}$ to create a LeuZ variant ( $3^{\prime} E T S^{\text {LeuZ mut }}$ ) unable to pair with RyhB sRNA. (C) Northern blot analysis to determine steady-state levels of $3^{\prime}$ ETS ${ }^{\text {LeuZ }}$ in wild-type and derived isogenic pcnB and $3^{\prime}$ ETS $^{\text {leuZ }}$ mutant strains under RyhB inducing and noninducing conditions, as described above. Northern blots showing transcript steady-state levels of $3^{\prime}$ ETS LeuZ and RyhB in a WT (fur ${ }^{+} ;$NRD1138) and derived isogenic mutants $3^{\prime}$ ETS leuZ WT (fur leuZ-kan; NRD1579), 3'ETSleuZ mut (fur $^{+} 3^{\prime}$ ETS $^{\text {leuZ mut }}$-kan; NRD1581), $\Delta$ pcnB (fur ${ }^{+} \Delta$ pcnB; NRD1198), $\Delta$ pcnB $3^{\prime}$ ETS $^{\text {leuz WT }}$ (fur ${ }^{+} \Delta$ pcnB leuZ-kan; NRD1585), $\Delta$ pcnB $3^{\prime} E T S^{\text {leuZ mut }}$ ( fur ${ }^{+} \Delta$ pcnB $3^{\prime}$ ETS $^{\text {leuZ }}$ mut $_{-k a n}$; NRD1587). ssrA was used as the loading control. Experiment was performed in triplicate and representative blots are shown. LeuZ term probe (Supplemental Table S2) was used to determine LeuZ and $3^{\prime} E T S^{\text {LeuZ }}$ levels. $(D, E)$ Determination of RyhB intrinsic stability in a strain encoding the wild-type $3^{\prime}$ ETS ${ }^{\text {LeuZ }}\left(3^{\prime}\right.$ ETS leuZ WT; NRD1579) or mutant $3^{\prime}$ ETS ${ }^{\text {LeuZ }}$ (3'ETS leuZ mut; NRD1585) and derived $\triangle p c n B$ strains, NRD1581 and NRD1587, respectively. RNA stability time-course experiments were performed as described in the legend of Figure 4. Representative northern blots are shown in C. (D) RyhB decay curves were generated as described in Figure 4 and corresponding half-life measurements are listed in Table 1. RyhB decay curves of WT (NRD1138) and its derived isogenic $\Delta p c n B$ strain (NRD1198) are included in $D$ as a reference. Points and error bars in the curves represent the means and the standard errors (SEM) of at least three independent experiments. Probes used are listed in Supplemental Table S2.

assessed the steady-state levels of $3^{\prime} E T S^{\text {LeuZ }}$ in a $\Delta p c n B$ mutant strain under RyhB inducing (+dipyridyl) and noninducing (-dipyridyl) conditions. Northern blot analysis showed that in the pcnB deletion strain, steady-state levels of $3^{\prime}$ ETS ${ }^{\text {LeuZ }}$ were consistently higher relative to a wild-type strain in both the presence and absence of RyhB induction (Fig. 6A). Next, we investigated whether the increased levels of $3^{\prime}$ ETS ${ }^{\text {LeuZ }}$ in a pcnB mutant strain were driving RyhB decay. To test this, we introduced into $p c n B^{+}$and $\triangle p c n B$ strains a mutant $3^{\prime}$ ETS ${ }^{\text {LeuZ }}$ ( $3^{\prime}$ ETS $S^{\text {leuZ mut }}$ ) in which $4 \mathrm{nt}$ shown to be critical for pairing with RyhB (Lalaouna et al. 2015b) were replaced with the complementary base (Fig. $6 \mathrm{~B})$. These nucleotide changes in the $3^{\prime}$ ETS ${ }^{\text {LeuZ }}$ unexpectedly resulted in a decrease in expression to levels undetectable by northern blots (Fig. 6C; Supplemental Fig. S8); however, this result did not preclude us from assessing the impact of the $3^{\prime} E T S^{\text {LeuZ }}$ on RyhB expression in the $p c n B^{+}$and $\triangle p c n B$ strains. To test this, we then assayed for RyhB stability after transcription inhibition in the $p c n B^{+}$and $\Delta p c n B$ strains that express the wild-type or mutated $3^{\prime} E T S^{\text {LeuZ }}$. As shown in Figure 6D,E and Table 1, the RyhB stability defect observed in a $\triangle p c n B$ mutant was 
completely suppressed by introduction of these mutations in the pairing region of $3^{\prime}$ ETS ${ }^{\text {Leuz }}$. Consistently, the introduction of the $3^{\prime}$ ETS leuz mut also restored the defect in RyhB steady-state levels of a $\Delta p c n B$ mutant to wildtype levels (Fig. 6C; Supplemental Fig. S8). Taken together our data demonstrated that the increased decay of RyhB in the absence of PAP I was due to pairing with $3^{\prime} E T S^{\text {LeuZ }}$.

\section{DISCUSSION}

More than two decades ago, a role for PAP I in mediating the decay of anti-sense sRNAs was discovered (He et al. 1993; Xu et al. 1993). A contemporaneous study demonstrated that PAP I also drives mRNA decay by providing a signal for other ribonucleases (O'Hara et al. 1995). Subsequent work demonstrated a role for PAP I in mediating the decay of anti-sense sRNAs and sRNAs not associated with Hfq (Dam Mikkelsen and Gerdes 1997; Söderbom et al. 1997; Söderbom and Wagner 1998; SzalewskaPalasz et al. 1998; Viegas et al. 2007; Maes et al. 2017). Here, we provide for the first time evidence that PAP I increases the stability of two Hfq-binding sRNAs, RyhB and MicA. Absence of PAP I led to a decrease in RyhB stability (Figs. 1D, 4F) resulting in a defect in RyhB-mediated gene regulation (Fig. 3). These findings indicated a previously unknown role of PAP I in regulating sRNA function and thus raised interesting questions about the mechanism by which this protein can contribute to sRNA stability.

\section{Mechanism of poly(A) polymerase mediated stabilization of sRNAs}

How does PAP I stabilize Hfq-dependent sRNAs such as RyhB? One possibility was that PAP I-dependent stabilization of RyhB resulted from direct polyadenylation of the sRNA leading to an increase in sRNA binding to $\mathrm{Hfq}$, thereby protecting it against RNase $\mathrm{E}$ cleavage. This mechanism would be analogous to the mechanism that has been described for PAP I in assisting mRNAs in binding $\mathrm{Hfq}$, i.e., Rho-independent terminators at the $3^{\prime}$ ends of mRNAs are preferentially polyadenylated by the Hfq-PAP I complex, which subsequently results in formation of a stable complex between $\mathrm{Hfq}$ and mRNAs (Mohanty and Kushner 2008; Mohanty et al. 2004; Régnier and Hajnsdorf 2013). However, our data does not support this hypothesis. Firstly, we failed to detect poly(A) tails at the ends of fulllength RyhB sRNA using 3' RACE (Supplemental Fig. S9). This result is consistent with the findings of a recent study examining the global landscape of polyadenylated RNAs in E. coli, in which no Hfq-dependent sRNAs were among the polyadenylated transcripts identified (Maes et al. 2017). In fact, the sRNAs that were found to be polyadenylated in this study were either anti-sense sRNAs (i.e., sRNAs that regulate mRNAs transcribed from the opposing DNA strand) or sRNAs that bind the RNA chaperone ProO. Secondly, the relative amounts of RyhB that coimmunoprecipitated with $\mathrm{Hfq}$ between a $\Delta$ pcnB mutant and a wild-type strain under iron starvation were not significantly different (Fig. 4C,D). Altogether, these findings indicated that PAP I mediated stabilization of RyhB was indirect.

Our finding that the RyhB stability defect in a $\triangle p c n B$ mutant was suppressed by introduction of a Y25D substitution in the distal face of $\mathrm{Hfq}$ (Fig. 4E,F) which is known to be important for facilitating sRNA-mRNA target interactions (Zhang et al. 2013; Schu et al. 2015) instead pointed toward a model where PAP I is stabilizing RyhB by protecting it from pairing-mediated decay. Further support for this model came from our results showing that RyhB stability in the $\Delta$ pcnB mutant increased to wild-type levels (Table 1; Fig. 5D,E) by introduction of a mutation in ryhB (ryhBmut) that blocked pairing with its target RNAs (Fig. 5A-C).

What was the RNA target that was accumulating in the absence of PAP I and driving the decay of RyhB? Over a hundred distinct RNA targets have been shown to be regulated by RyhB (Massé et al. 2005; Lalaouna et al. 2015b; Wang et al. 2015; Melamed et al. 2016); therefore, there were many possible candidates that could have been driving the decay and depletion of RyhB in the $\Delta p c n B$ strain background. Interestingly, recent work by Maes et al. (2017) identified 14 distinct RNA targets of RyhB that were subjected to polyadenylation in E. coli. Furthermore, a subset of these RyhB targets such as leuZ, $\operatorname{csp} B, s d h C, s d h D, s d h A, s d h B$, fur, and uof were also reported to be up-regulated in the absence of PAP I (Mohanty and Kushner 2006; Maes et al. 2017). Of note here is the LeuZ precursor tRNA encoded by leuZ, which was one of the RyhB targets that was highly up-regulated in a $\Delta p c n B$ mutant (Maes et al. 2017). Past studies also pointed toward a critical role of PAP I in promoting the degradation of the $3^{\prime}$ ETS ${ }^{\text {LeuZ }}$ by exoribonucleases following its excision from the LeuZ precursor tRNA by RNase E (Li and Deutscher 2002; Ow and Kushner 2002). More importantly, it was recently shown that $3^{\prime}$ ETS ${ }^{\text {LeuZ }}$ can pair with RyhB sRNA and down-regulate RyhB transcript levels, which in turn leads to decreased regulation of RyhB targets including the sodB and sdhCDAB mRNAs (Lalaouna et al. $2015 a, b)$. Based on these findings, we hypothesized that PAP I promotes the exoribonucleolytic decay of the $3^{\prime}$ ETS $^{\text {LeuZ }}$ through polyadenylation of this transcript (Fig. 7A). Furthermore, we postulated that in the absence of PAP I, 3'ETS ${ }^{\text {LeuZ }}$ accumulates and drives RNase E-mediated decay of RyhB as a result of base-pairing with this SRNA leading to loss of regulation of its other target mRNAs including sodB and sdhCDAB (Fig. 7B). In support of this hypothesis, we found that introduction of a mutation in $3^{\prime}$ ETS $^{\text {leuZ }}$ (3'ETS leuZ mut) that was previously shown to block pairing of $3^{\prime}$ ETS $^{\text {LeuZ }}$ with RyhB sRNA (Lalaouna et al. $2015 b)$ suppressed the RyhB stability defect of a $\Delta$ pcnB mutant (Table 1; Fig. 6D,E) and led to a significant increase 
A

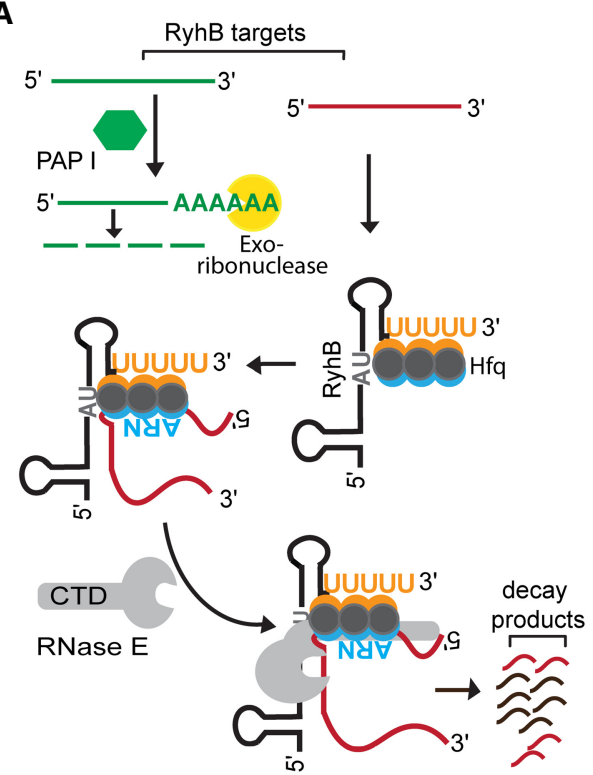

B

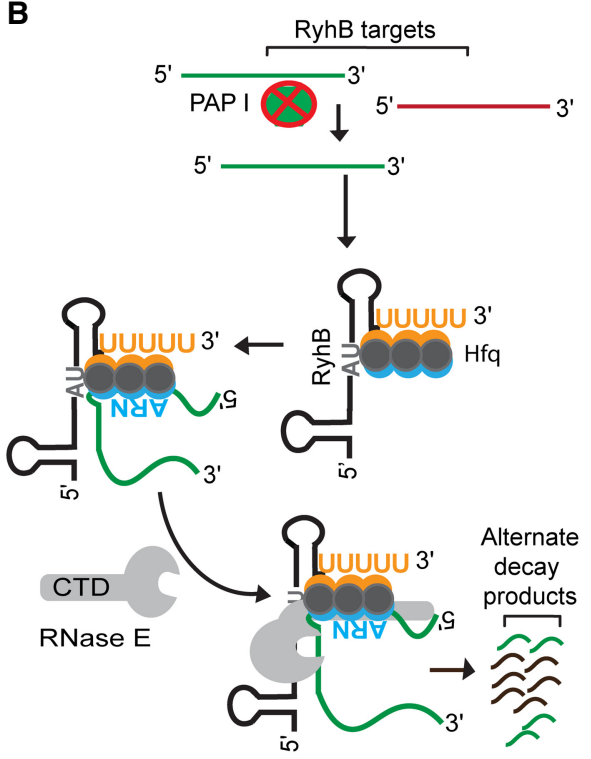

FIGURE 7. Model for poly(A) polymerase-mediated regulation of RyhB stability. (A) Poly(A) polymerase (PAP I) stabilizes RyhB by facilitating the degradation of $3^{\prime} E T S^{\text {LeuZ }}$ (green-colored RNA) through the addition of poly(A) tails, which provide a toe-hold for exoribonucleases. As a result, RyhB is abundant and able to bind and efficiently regulate other mRNA targets (collectively represented by the red-colored RNA), which are subsequently degraded by RNase E along with RyhB. (B) In a strain lacking poly(A) polymerase, $3^{\prime}$ ETS LeuZ (green-colored RNA) accumulates and binds to RyhB leading to RNase E-mediated decay of this sRNA. RyhB levels are thereby reduced, and certain mRNA targets (red-colored RNA) accumulate that would otherwise be negatively regulated by this sRNA.

in RyhB steady-state levels (Fig. 6C; Supplemental Fig. S8). Decreased RyhB stability in the $\triangle p c n B$ mutant subsequently resulted in an impaired regulation of the $\operatorname{sod} B$ and sdhCDAB mRNAs (Figs. 3, 5B; Supplemental Fig. $\mathrm{S} 2, \mathrm{~S} 3, \mathrm{~S} 6, \mathrm{~S} 7)$. This reduced regulation of $\mathrm{sdhCDAB}$ by RyhB in the absence of PAP I has a measurable impact on $E$. coli physiology resulting in the ability of a $\Delta p c n B$ $\Delta$ fur strain to grow on succinate as the sole carbon source (Supplemental Fig. S7).

Interestingly, several examples have now been described of target RNAs that drive the decay of sRNAs resulting in reduced regulation of other mRNAs. The first reported example in this category in E. coli and Salmonella enterica was described by Plumbridge et al. (2014) who demonstrated that pairing of an $\mathrm{Hfq}$-dependent sRNA (ChiX) with one target mRNA (chbBC) drove the decay of that sRNA. This depletion of ChiX resulted in impaired regulation of another one of its targets, the chiP mRNA (Figueroa-Bossi et al. 2009). Subsequently, Miyakoshi et al. (2015) demonstrated that the SroC sRNA generated in the decay of the glt|JKL transcript in E. coli and Salmonella enterica functioned to titrate GcvB levels (Miyakoshi et al. 2015).

\section{Mechanisms by which poly(A) polymerase and $\mathrm{Hfq}$ block RNase E-mediated decay of sRNAs are distinct}

The endoribonuclease RNase $\mathrm{E}$ is a key protein involved in degrading both Hfq-dependent sRNAs and cleaving tar- get mRNAs upon sRNA-mRNA pairing (De Lay et al. 2013). The N-terminal domain of RNase $E$ contains the catalytic site, but can also bind RNA through its S1 domain and the $5^{\prime}$ sensor domain as well as its active site residues (Garrey et al. 2009). The C-terminal domain (CTD) of RNase E contains two RNA binding sites, the ARRBD and AR2 regions, in addition to binding sites for other proteins including enolase, the RNA helicase RhIB, and the $3^{\prime} \rightarrow 5^{\prime}$ exoribonuclease PNPase (Mackie 2013). The results of two previous studies suggested that $\mathrm{Hfq}$ interacts directly with the CTD of RNase E (Morita et al. 2005; lkeda et al. 2011), but detailed biochemical studies indicate that Hfq interacts with the CTD via RNA (Worrall et al. 2008). The CTD was also previously shown to be important for coupled degradation of RyhB with its target mRNAs (Massé et al. 2003; Desnoyers and Massé 2012). It is notable that the defect in RyhB stability that was observed in a $\triangle p c n B$ mutant was suppressed by introduction of an rne-131 allele encoding an RNase E lacking the CTD (Figs. 1C,D, 5D,F), whereas introduction of an rne-131 mutation failed to suppress the RyhB stability defect of an $\Delta h f q$ mutant (Figs. 1C,D, 5D,F). Since RyhB decay in the $\Delta p c n B$ strain was due to pairing with the $3^{\prime}$ ETS ${ }^{\text {LeuZ }}$, these results demonstrated a requirement for the CTD of RNase $E$ for degradation of RyhB upon pairing with the $3^{\prime}$ ETS ${ }^{\text {LeuZ }}$, which may indicate that one or both of the RNA binding regions, ARRBD and AR2, mediate the recruitment of this sRNA to RNase E after pairing with target RNAs. 
However, an alternative interpretation of our results is that the RNA degradosome was required for the degradation of RyhB after sRNA-mRNA pairing as the CTD is important for the assembly of the RNA degradosome, which includes enolase, the RNA helicase RhIB, and PNPase. In contrast, the inconsequential role of the CTD in decay of RyhB in the $\Delta h f q$ strain may signify that the $\mathrm{N}$-terminal catalytic domain of RNase $E$ is sufficient to cleave RyhB when it is not associated with Hfq or RNA targets.

\section{Impact of poly(A) polymerase on a subset of Hfq-dependent sRNAs}

As mentioned above, sRNAs can be classified into two distinct classes based on their interactions with Hfq (Zhang et al. 2013; Schu et al. 2015). Class I sRNAs interact with proximal face and rim of $\mathrm{Hfq}$, and their mRNA targets bind the distal face of $\mathrm{Hfq}$ (Fig. 4E). In contrast, Class II sRNAs interact with the proximal and distal faces of $\mathrm{Hfq}$, and their target mRNAs bind along the rim. The fact that deletion of pcnB led to a defect in the stability of MicA in addition to RyhB (two Class I sRNAs) but did not significantly impact the turnover of GcvB or Class II sRNAs such as ChiX, CyaR, and MgrR (Fig. 2A-E; Supplemental Fig. S1) is interesting. Whether this difference in the ability of PAP I to impact the stability of MicA and RyhB, but not ChiX, CyaR, and MgrR was due to the fact that these sRNAs interact with $\mathrm{Hfq}$ differently or was a coincidence will need to be resolved in future studies. Regardless, the ability of PAP I to impact a specific subset of sRNAs by a mechanism that is distinct from $\mathrm{Hfq}$ suggests an additional layer of complexity in sRNA-mediated gene regulation.

\section{MATERIALS AND METHODS}

\section{Bacterial strains and growth conditions}

All strains and plasmids used in this study are derivatives of $E$. coli K-12 strain MG1655 (rph-1) and are listed in Supplemental Table S1. Primers used for strain construction are listed in Supplemental Table S2. Strain construction is described in Supplemental Materials and Methods.

All strains were grown in liquid medium or agar plates containing either Lennox broth (LB), M9 minimal medium supplemented with $0.001 \%$ vitamin $\mathrm{B} 1$ and $0.2 \%$ glucose or succinate, or MOPS EZ rich defined medium (Teknova) supplemented with $0.4 \%$ glycerol instead of glucose. Antibiotics were used in the following final concentrations: ampicillin, $100 \mu \mathrm{g} / \mathrm{mL}$; kanamycin, $25 \mu \mathrm{g} / \mathrm{mL}$; chloramphenicol, $25 \mu \mathrm{g} / \mathrm{mL}$ or $10 \mu \mathrm{g} / \mathrm{mL}$ (for any mutant(s) containing hfq deletion), tetracycline, $12.5 \mu \mathrm{g} / \mathrm{mL}$, zeocin, $25 \mu \mathrm{g} /$ $\mathrm{mL}$, and rifampicin, $250 \mu \mathrm{g} / \mathrm{mL}$. 2, 2' dipyridyl was added to liquid medium at a final concentration of $250 \mu \mathrm{M}$. All liquid cultures and bacteria on solid medium were grown aerobically at $37^{\circ} \mathrm{C}$. Overnight cultures were diluted 1:200 fold in appropriate medium and grown until desired densities were reached. Growth was determined by measuring the optical densities of liquid cultures at $600 \mathrm{~nm}\left(\mathrm{OD}_{600}\right)$. Cultures were considered to be in expo- nential phase when they reached $\mathrm{OD}_{600}$ between 0.3 and 0.4 in $\mathrm{LB}$ or $\mathrm{OD}_{600}$ of $\sim 1.0$ in MOPS EZ rich defined medium.

\section{RNA extraction}

Total RNA was extracted from exponential phase cultures growing either in LB or in MOPS EZ rich defined medium using hot phenol lysis method described previously (Massé et al. 2003). Briefly $700 \mu \mathrm{L}$ of samples were removed from growing cultures and added to a mixture containing $800 \mu \mathrm{L}$ of acid phenol-chloroform-isoamyl alcohol ( $\mathrm{pH}$ of 4.3; Fisher Scientific) and $100 \mu \mathrm{L}$ of lysis buffer (320 mM sodium acetate [pH 4.6], 8\% SDS, $16 \mathrm{mM}$ EDTA) equilibrated to $65^{\circ} \mathrm{C}$. Samples were mixed at $65^{\circ} \mathrm{C}$ for 5 min and centrifuged for $30 \mathrm{~min}$ at $4^{\circ} \mathrm{C}$ to separate phases. The upper aqueous phase was extracted a second time with equal volume of neutral phenol-chloroform-isoamyl alcohol $(\mathrm{pH}$ of 6.7; Fisher Scientific). RNA was alcohol-precipitated and resuspended in DEPC-treated water. RNA concentration was measured using Nano Drop 2000 (Thermo Fisher Scientific).

\section{RNA stability assay}

To determine RNA stabilities for sRNAs in different mutants constructed in the fur ${ }^{+}$background (Supplemental Table S1) all cultures were grown to exponential phase. RyhB or MicA expression were induced from a ryhB promoter by the addition of dipyridyl (iron chelator) while CyaR expression was induced from its native promoter by the addition of cyclic AMP (Adenosine $3^{\prime}$, 5 - cyclic monophosphate sodium salt monohydrate, Sigma) at a $5 \mathrm{mM}$ final concentration. Under exponential growth conditions expression of MgrR, GcvB, and ChiX is constitutive. After 15 min of sRNA expression a culture sample ( $\left.T_{0}\right)$ was collected. Following that, rifampicin was added to inhibit all further transcription and additional samples were collected 1, 2, 4, and 6 min after rifampicin addition. To determine RyhB stability in mutants constructed in a fur deletion background strains were grown in MOPS EZ rich defined medium to exponential phase and a culture sample was collected $\left(T_{0}\right)$. Rifampicin was added to all cultures to inhibit transcription and additional samples were collected at 2, 5, 10, 15, and 30 min after rifampicin addition. All samples were subjected to RNA extraction as described above.

\section{Northern blot analysis}

Two micrograms of each RNA sample was loaded on $5 \%$ or $10 \%$ Criterion TBE-urea precast gels (Bio-Rad) and electrophoresed at $70 \mathrm{~V}$. Next, the RNA samples were transferred to a Zeta-Probe GT membrane (Bio-Rad) using a Trans-Blot SD semidry transfer apparatus (Bio-rad) following manufacturer's guidelines. Transferred RNA was UV crosslinked and hybridized overnight with $100 \mathrm{ng} /$ $\mathrm{mL}$ of $5^{\prime}$ biotinylated DNA probe (Supplemental Table S2) in ULTRAhyb (Ambion) hybridization buffer at $42^{\circ} \mathrm{C}$. Blots were developed using a BrightStar BioDetect kit protocol (Ambion), imaged with a ChemiDoc MP imager (Bio-Rad) and quantified using Image Lab software version 5.2.1 (Bio-Rad). Signal intensity corresponding to each sRNA or mRNA was normalized to that of either ssrA or 5S rRNA, which served as internal loading controls. Decay curves corresponding to RNA stability time course experiments were generated by using GraphPad Prism version 5.0. 


\section{Quantitative RT-PCR (qRT-PCR) analysis}

RNA extracted from exponential growth phase cultures as described above was subjected to DNase treatment (DNase Turbo; Ambion) following manufacturer's protocol. Sample mixtures (total reaction volume of $100 \mu \mathrm{L}$ ) were incubated for $1 \mathrm{~h}$ at $37^{\circ} \mathrm{C}$ and reaction was stopped by addition of $100 \mu \mathrm{L}$ of DEPCtreated water and $200 \mu \mathrm{L}$ of neutral phenol-chloroform-isoamyl alcohol (Fisher). DNase treated RNA samples were phenol extracted, alcohol precipitated and RNA concentration was measured as described above. Samples were then tested for the presence of any contaminating DNA by PCR using gene specific qRT-PCR primers (Supplemental Table S2) before proceeding to downstream applications. One microgram of DNA-free RNA was reverse transcribed using random hexamers and Superscript III Reverse Transcriptase (RT) (Invitrogen) following manufacturer's protocol. For each sample a no RT (NRT) control reaction was performed. cDNA samples were diluted 1:100-fold and $2 \mu \mathrm{L}$ of diluted samples (resulting from both RT- and NRT- PCR) were used in a qRT-PCR reaction mixture containing $10 \mu \mathrm{L}$ of iTaq Universal SYBR Green Supermix (Bio-Rad) and $2 \mu \mathrm{L}$ each of $4 \mu \mathrm{M}$ qPCR primers (Supplemental Table S2). A single no template control (NTC) for each qPCR primer pair used in this study was also included. Data were collected using an CFX connect Real Time thermocycler (Bio-Rad) running the SYBR Green with melt curve program modified as per the manufacturer's recommendations. Reactions were performed with two technical duplicates using cDNA samples from at least three independent biological replicates per strain and ssrA was used as the internal reference for normalization. The $\Delta \Delta C_{t}$ method was used to calculate fold changes of transcripts corresponding to target genes in different sets of mutants relative to the wild-type parent. Statistical analysis was performed using one-way ANOVA (and nonparametric) in GraphPad Prism version 5.0 .

\section{Protein extraction and western blot analysis}

Overnight cultures of wild-type and mutant strains were subcultured into fresh $10 \mathrm{~mL} \mathrm{LB}$ and grown to exponential phase. Protein extraction was performed as described previously (De Lay and Gottesman 2011). Briefly, $1.0 \mathrm{~mL}$ of culture from each strain was subjected to TCA precipitation, washed once with $80 \%$ cold acetone solution, air dried, suspended in $2 \times$ Laemmli sample buffer (Bio-Rad) containing freshly added $5 \%$ (vol/vol) $\beta$ mercaptoethanol and heated at $95^{\circ} \mathrm{C}$ for $10 \mathrm{~min}$. Total protein amount was normalized to corresponding $\mathrm{OD}_{600}$ of each specific culture. Approximately $0.08 \mathrm{OD}_{600}$ units of total protein from each strain was separated on a $4 \%$ stacking $10 \%$ resolving SDSPAGE gel in $1 \times$ Tris-glycine SDS buffer at $120 \mathrm{~V}$. Fractionated protein was then transferred to a $0.45 \mu \mathrm{m}$ PVDF membrane (Thermo Scientific) at $15 \mathrm{~V}$ for 30 min using Trans-Blot SD semidry transfer apparatus (Bio-rad) following manufacturer's guidelines.

Hfq was detected using 1:5000 dilution of preabsorbed anti-Hfq antiserum obtained from Dr. Susan Gottesman (NCl) and goat antirabbit lgG secondary antibody. For detection of DnaK (loading control) 1:10,000 dilution of mouse anti-DnaK monoclonal antibody (Abcam) and anti-mouse goat secondary antibody (Santa Cruz Biotechnologies, Inc.) were used following manufacturer's guidelines. All secondary antibodies were conjugated to alkaline phosphatase and were visualized by using Immun-Star AP sub- strate (Bio-Rad) and ChemiDoc MP imager (Bio-Rad). Signal intensity was quantitated using Image Lab software (Bio-Rad).

\section{Hfq coimmunoprecipitation}

Immunoprecipitation with $\mathrm{Hfq}$ was performed as described previously (Bandyra et al. 2016) with few modifications. Briefly, overnight cultures were diluted 200-fold into $30 \mathrm{~mL}$ of fresh LB liquid medium and grown to an $\mathrm{OD}_{600}$ of $\sim 0.3$. Dipyridyl was added to induce RyhB expression for $15 \mathrm{~min}$ and $25 \mathrm{~mL}$ aliquots of cells were pelleted, washed, and frozen as previously described (Zhang et al. 2003). Immunoprecipitations were performed as previously described (Zhang et al. 2002) using anti-Hfq antiserum obtained from Dr. Susan Gottesman (NCI). RNA was isolated by phenol extraction and northern blots were performed as described in Materials and Methods.

\section{SUPPLEMENTAL MATERIAL}

Supplemental material is available for this article.

\section{ACKNOWLEDGMENTS}

We thank Gisela Storz for her comments on the manuscript. This work, including the efforts of D.S., L.M.M., T.A.C., and N.R.D., was funded by the McGovern Medical School (University of Texas Health Science Center at Houston: Startup Funds) and $\mathrm{HHS}|\mathrm{NIH}|$ National Institute of General Medical Sciences (NIGMS; R01GM121368). The content of this publication is solely the responsibility of the authors and does not necessarily represent the official views of the National Institutes of Health.

Received May 3, 2018; accepted July 24, 2018.

\section{REFERENCES}

Andrade JM, Arraiano CM. 2008. PNPase is a key player in the regulation of small RNAs that control the expression of outer membrane proteins. RNA 14: 543-551.

Andrade JM, Pobre V, Matos AM, Arraiano CM. 2012. The crucial role of PNPase in the degradation of small RNAs that are not associated with Hfq. RNA 18: 844-855.

Bandyra KJ, Said N, Pfeiffer V, Górna MW, Vogel J, Luisi BF. 2012. The seed region of a small RNA drives the controlled destruction of the target mRNA by the endoribonuclease RNase E. Mol Cell 47: 943-953.

Bandyra KJ, Sinha D, Syrjanen J, Luisi BF, De Lay NR. 2016. The ribonuclease polynucleotide phosphorylase can interact with small regulatory RNAs in both protective and degradative modes. RNA 22: 360-372.

Bardill JP, Hammer BK. 2012. Non-coding sRNAs regulate virulence in the bacterial pathogen Vibrio cholerae. RNA Biol 9: 392-401.

Bobrovskyy M, Vanderpool CK. 2013. Regulation of bacterial metabolism by small RNAs using diverse mechanisms. Annu Rev Genet 47: 209-232.

Caldelari I, Chao Y, Romby P, Vogel J. 2013. RNA-mediated regulation in pathogenic bacteria. Cold Spring Harb Perspect Med 3: a010298.

Callaghan AJ, Aurikko JP, llag LL, Günter Grossmann J, Chandran V, Kühnel K, Poljak L, Carpousis AJ, Robinson CV, Symmons MF, 
et al. 2004. Studies of the RNA degradosome-organizing domain of the Escherichia coli ribonuclease RNase E. J Mol Biol 340: 965-979.

Cameron TA, De Lay NR. 2016. The phosphorolytic exoribonucleases polynucleotide phosphorylase and RNase PH stabilize sRNAs and facilitate regulation of their mRNA targets. J Bacteriol 198: 3309-3317.

Dam Mikkelsen N, Gerdes K. 1997. Sok antisense RNA from plasmid $\mathrm{R} 1$ is functionally inactivated by RNase $\mathrm{E}$ and polyadenylated by poly(A) polymerase I. Mol Microbiol 26: 311-320.

De Lay N, Gottesman S. 2011. Role of polynucleotide phosphorylase in sRNA function in Escherichia coli. RNA 17: 1172-1189.

De Lay N, Schu DJ, Gottesman S. 2013. Bacterial small RNA-based negative regulation: $\mathrm{Hfq}$ and its accomplices. J Biol Chem 288: 7996-8003.

Desnoyers G, Massé E. 2012. Noncanonical repression of translation initiation through small RNA recruitment of the RNA chaperone Hfq. Genes Dev 26: 726-739.

Durand S, Storz G. 2010. Reprogramming of anaerobic metabolism by the FnrS small RNA. Mol Microbiol 75: 1215-1231.

Felden B, Cattoir V. 2018. Bacterial adaptation to antibiotics through regulatory RNAs. Antimicrobial Agents Chemother 62: e0250317.

Felden B, Vandenesch F, Bouloc P, Romby P. 2011. The Staphylococcus aureus RNome and its commitment to virulence. PLoS Pathog 7: e1002006.

Figueroa-Bossi N, Valentini M, Malleret L, Fiorini F, Bossi L. 2009. Caught at its own game: regulatory small RNA inactivated by an inducible transcript mimicking its target. Genes Dev 23: 2004-2015.

Garrey SM, Blech M, Riffell JL, Hankins JS, Stickney LM, Diver M, Hsu YH, Kunanithy V, Mackie GA. 2009. Substrate binding and active site residues in RNases $\mathrm{E}$ and $\mathrm{G}$ : role of the $5^{\prime}$-sensor. J Biol Chem 284: 31843-31850.

Gimpel M, Heidrich N, Mäder U, Krügel H, Brantl S. 2010. A dual-function sRNA from $B$. subtilis: SR1 acts as a peptide encoding mRNA on the gapA operon. Mol Microbiol 76: 990-1009.

Gonzalez GM, Durica-Mitic S, Hardwick SW, Moncrieffe MC, Resch M, Neumann P, Ficner R, Görke B, Luisi BF. 2017. Structural insights into RapZ-mediated regulation of bacterial amino-sugar metabolism. Nucleic Acids Res 45: 10845-10860.

Gripenland J, Netterling S, Loh E, Tiensuu T, Toledo-Arana A, Johansson J. 2010. RNAs: regulators of bacterial virulence. Nat Rev Microbiol 8: 857-866.

Hajnsdorf E, Régnier P. 2000. Host factor Hfq of Escherichia coli stimulates elongation of poly $(A)$ tails by poly $(A)$ polymerase I. Proc Natl Acad Sci 97: 1501-1505.

He L, Söderbom F, Wagner EG, Binnie U, Binns N, Masters M. 1993. $\mathrm{PcnB}$ is required for the rapid degradation of RNAl, the antisense RNA that controls the copy number of ColE1-related plasmids. Mol Microbiol 9: 1131-1142.

Hébrard M, Kröger C, Srikumar S, Colgan A, Händler K, Hinton JC. 2012. sRNAs and the virulence of Salmonella enterica serovar Typhimurium. RNA Biol 9: 437-445.

Holmqvist E, Wagner EGH. 2017. Impact of bacterial sRNAs in stress responses. Biochem Soc Trans 45: 1203-1212.

Ikeda Y, Yagi M, Morita T, Aiba H. 2011. Hfq binding at RhIB-recognition region of $\mathrm{RNase} E$ is crucial for the rapid degradation of target mRNAs mediated by sRNAs in Escherichia coli. Mol Microbiol 79: 419-432.

Jørgensen MG, Thomason MK, Havelund J, Valentin-Hansen P, Storz G. 2013. Dual function of the McaS small RNA in controlling biofilm formation. Genes Dev 27: 1132-1145.

Koo JT, Alleyne TM, Schiano CA, Jafari N, Lathem WW. 2011. Global discovery of small RNAs in Yersinia pseudotuberculosis identifies
Yersinia-specific small, noncoding RNAs required for virulence. Proc Natl Acad Sci 108: E709-E717.

Lalaouna D, Carrier MC, Massé E. 2015a. The shock absorber: preventing sRNA transcriptional noise. Cell Cycle 14: 2539-2540.

Lalaouna D, Carrier MC, Semsey S, Brouard JS, Wang J, Wade JT, Massé E. 2015b. A 3' external transcribed spacer in a tRNA transcript acts as a sponge for small RNAs to prevent transcriptional noise. Mol Cell 58: 393-405.

Le Derout J, Folichon M, Briani F, Deho G, Régnier P, Hajnsdorf E. 2003. Hfq affects the length and the frequency of short oligo(A) tails at the $3^{\prime}$ end of Escherichia coli rpsO mRNAs. Nucleic Acids Res 31: 4017-4023.

Lease RA, Woodson SA. 2004. Cycling of the Sm-like protein Hfq on the DsrA small regulatory RNA. J Mol Biol 344: 1211-1223.

Li Z, Deutscher MP. 2002. RNase E plays an essential role in the maturation of Escherichia coli tRNA precursors. RNA 8: 97-109.

Mackie GA. 2013. RNase E: at the interface of bacterial RNA processing and decay. Nat Rev Microbiol 11: 45-57.

Maes A, Gracia C, Innocenti N, Zhang K, Aurell E, Hajnsdorf E. 2017. Landscape of RNA polyadenylation in E. coli. Nucleic Acids Res 45: 2746-2756.

Mandin P, Chareyre S, Barras F. 2016. A regulatory circuit composed of a transcription factor, IscR, and a regulatory RNA, RyhB, controls Fe-S cluster delivery. mBio 7: e00966.

Mann B, van Opijnen T, Wang J, Obert C, Wang YD, Carter R, McGoldrick DJ, Ridout G, Camilli A, Tuomanen El, et al. 2012. Control of virulence by small RNAs in Streptococcus pneumoniae. PLoS Pathog 8: e1002788.

Massé E, Gottesman S. 2002. A small RNA regulates the expression of genes involved in iron metabolism in Escherichia coli. Proc Natl Acad Sci 99: 4620-4625.

Massé E, Escorcia FE, Gottesman S. 2003. Coupled degradation of a small regulatory RNA and its mRNA targets in Escherichia coli. Genes Dev 17: 2374-2383.

Massé E, Vanderpool CK, Gottesman S. 2005. Effect of RyhB small RNA on global iron use in Escherichia coli. J Bacteriol 187: 6962-6971.

Massé E, Salvail H, Desnoyers G, Arguin M. 2007. Small RNAs controlling iron metabolism. Curr Opin Microbiol 10: 140-145.

McClure R, Balasubramanian D, Sun Y, Bobrovskyy M, Sumby $P$, Genco CA, Vanderpool CK, Tjaden B. 2013. Computational analysis of bacterial RNA-Seq data. Nucleic Acids Res 41: e140.

Melamed S, Peer A, Faigenbaum-Romm R, Gatt YE, Reiss N, Bar A, Altuvia Y, Argaman L, Margalit H. 2016. Global mapping of small RNA-target interactions in bacteria. Mol Cell 63: 884-897.

Miyakoshi M, Chao Y, Vogel J. 2015. Regulatory small RNAs from the $3^{\prime}$ regions of bacterial mRNAs. Curr Opin Microbiol 24: 132-139.

Mohanty BK, Kushner SR. 2006. The majority of Escherichia coli mRNAs undergo post-transcriptional modification in exponentially growing cells. Nucleic Acids Res 34: 5695-5704.

Mohanty BK, Kushner SR. 2008. Rho-independent transcription terminators inhibit RNase $P$ processing of the secG leuU and metT tRNA polycistronic transcripts in Escherichia coli. Nucleic Acids Res 36: 364-375.

Mohanty BK, Kushner SR. 2011. Bacterial/archaeal/organellar polyadenylation. Wiley Interdiscip Rev RNA 2: 256-276.

Mohanty BK, Kushner SR. 2016. Regulation of mRNA decay in bacteria. Annu Rev Microbiol 70: 25-44.

Mohanty BK, Maples VF, Kushner SR. 2004. The Sm-like protein $\mathrm{Hfq}$ regulates polyadenylation dependent mRNA decay in Escherichia coli. Mol Microbiol 54: 905-920.

Moll I, Afonyushkin T, Vytvytska O, Kaberdin VR, Bläsi U. 2003. Coincident $\mathrm{Hfq}$ binding and RNase $\mathrm{E}$ cleavage sites on mRNA and small regulatory RNAs. RNA 9: 1308-1314. 
Møller T, Franch T, Udesen C, Gerdes K, Valentin-Hansen P. 2002a. Spot 42 RNA mediates discoordinate expression of the E. coli galactose operon. Genes Dev 16: 1696-1706.

Møller T, Franch T, Hojrup P, Keene DR, Bachinger HP, Brennan RG, Valentin-Hansen P. 2002b. Hfq: a bacterial Sm-like protein that mediates RNA-RNA interaction. Mol Cell 9: 23-30.

Morita T, Maki K, Aiba H. 2005. RNase E-based ribonucleoprotein complexes: mechanical basis of mRNA destabilization mediated by bacterial noncoding RNAs. Genes Dev 19: 2176-2186.

O'Hara EB, Chekanova JA, Ingle CA, Kushner ZR, Peters E, Kushner SR. 1995. Polyadenylylation helps regulate mRNA decay in Escherichia coli. Proc Natl Acad Sci 92: 1807-1811.

Ow MC, Kushner SR. 2002. Initiation of tRNA maturation by RNase $E$ is essential for cell viability in E. coli. Genes Dev 16: 1102-1115.

Pannuri A, Vakulskas CA, Zere T, McGibbon LC, Edwards AN, Georgellis D, Babitzke P, Romeo T. 2016. Circuitry linking the catabolite repression and $\mathrm{Csr}$ global regulatory systems of Escherichia coli. J Bacteriol 198: 3000-3015.

Parker A, Gottesman S. 2016. Small RNA regulation of TolC, the outer membrane component of bacterial multidrug transporters. J Bacteriol 198: 1101-1113.

Parker A, Cureoglu S, De Lay N, Majdalani N, Gottesman S. 2017. Alternative pathways for Escherichia coli biofilm formation revealed by sRNA overproduction. Mol Microbiol 105: 309-325.

Peterman N, Lavi-Itzkovitz A, Levine E. 2014. Large-scale mapping of sequence-function relations in small regulatory RNAs reveals plasticity and modularity. Nucleic Acids Res 42: 12177-12188.

Pfeiffer V, Papenfort K, Lucchini S, Hinton JC, Vogel J. 2009. Coding sequence targeting by MicC RNA reveals bacterial mRNA silencing downstream of translational initiation. Nat Struct Mol Biol 16: 840-846.

Plumbridge J, Bossi L, Oberto J, Wade JT, Figueroa-Bossi N. 2014. Interplay of transcriptional and small RNA-dependent control mechanisms regulates chitosugar uptake in Escherichia coli and Salmonella. Mol Microbiol 92: 648-658.

Prévost K, Desnoyers G, Jacques JF, Lavoie F, Massé E. 2011. Small RNA-induced mRNA degradation achieved through both translation block and activated cleavage. Genes Dev 25: 385-396.

Régnier P, Hajnsdorf E. 2013. The interplay of Hfq, poly(A) polymerase $I$ and exoribonucleases at the $3^{\prime}$ ends of RNAs resulting from Rho-independent termination: a tentative model. RNA Biol 10: 602-609.

Richards GR, Vanderpool CK. 2011. Molecular call and response: the physiology of bacterial small RNAs. Biochim Biophys Acta 1809: 525-531.

Ruiz-Larrabeiti O, Plágaro AH, Gracia C, Sevillano E, Gallego L, Hajnsdorf E, Kaberdin VR. 2016. A new custom microarray for sRNA profiling in Escherichia coli. FEMS Microbiol Lett 363: fnw131.

Rutherford ST, Bassler BL. 2012. Bacterial quorum sensing: its role in virulence and possibilities for its control. Cold Spring Harb Perspect Med 2: a012427.

Salvail H, Massé E. 2012. Regulating iron storage and metabolism with RNA: an overview of posttranscriptional controls of intracellular iron homeostasis. Wiley Interdiscip Rev RNA 3: 26-36.

Schu DJ, Zhang A, Gottesman S, Storz G. 2015. Alternative Hfq-sRNA interaction modes dictate alternative mRNA recognition. EMBO J 34: 2557-2573.

Sedlyarova N, Shamovsky I, Bharati BK, Epshtein V, Chen J, Gottesman S, Schroeder R, Nudler E. 2016. sRNA-mediated control of transcription termination in E. coli. Cell 167: 111-121.

Söderbom F, Wagner EG. 1998. Degradation pathway of CopA, the antisense RNA that controls replication of plasmid R1. Microbiol 144(Pt 7): 1907-1917.
Söderbom F, Binnie U, Masters M, Wagner EG. 1997. Regulation of plasmid R1 replication: $\mathrm{PcnB}$ and RNase E expedite the decay of the antisense RNA, CopA. Mol Microbiol 26: 493-504.

Soper TJ, Woodson SA. 2008. The rpoS mRNA leader recruits Hfq to facilitate annealing with DsrA sRNA. RNA 14: 1907-1917.

Storz G, Vogel J, Wassarman KM. 2011. Regulation by small RNAs in bacteria: expanding frontiers. Mol. Cell 43: 880-891.

Szalewska-Palasz A, Wrobel B, Wegrzyn G. 1998. Rapid degradation of polyadenylated oop RNA. FEBS Lett 432: 70-72.

Thomason MK, Fontaine F, De Lay N, Storz G. 2012. A small RNA that regulates motility and biofilm formation in response to changes in nutrient availability in Escherichia coli. Mol. Microbiol 84: 17-35.

Toledo-Arana A, Dussurget O, Nikitas G, Sesto N, Guet-Revillet H, Balestrino D, Loh E, Gripenland J, Tiensuu T, Vaitkevicius K, et al. 2009. The Listeria transcriptional landscape from saprophytism to virulence. Nature 459: 950-956.

Updegrove TB, Zhang A, Storz G. 2016. Hfq: the flexible RNA matchmaker. Curr Opin Microbiol 30: 133-138.

Vanzo NF, Li YS, Py B, Blum E, Higgins CF, Raynal LC, Krisch HM, Carpousis AJ. 1998. Ribonuclease E organizes the protein interactions in the Escherichia coli RNA degradosome. Genes Dev 12: 2770-2781.

Vecerek B, Moll I, Bläsi U. 2007. Control of Fur synthesis by the noncoding RNA RyhB and iron-responsive decoding. EMBO J 26: 965-975.

Viegas SC, Pfeiffer V, Sittka A, Silva IJ, Vogel J, Arraiano CM. 2007. Characterization of the role of ribonucleases in Salmonella small RNA decay. Nucleic Acids Res 35: 7651-7664.

Vogel J, Luisi BF. 2011. Hfq and its constellation of RNA. Nat Rev Microbiol 9: 578-589.

Wang J, Rennie W, Liu C, Carmack CS, Prévost K, Caron MP, Massé E, Ding Y, Wade JT. 2015. Identification of bacterial sRNA regulatory targets using ribosome profiling. Nucleic Acids Res 43: 10308-10320.

Waters LS, Storz G. 2009. Regulatory RNAs in bacteria. Cell 136: 615-628.

Waters SA, McAteer SP, Kudla G, Pang I, Deshpande NP, Amos TG, Leong KW, Wilkins MR, Strugnell R, Gally DL, et al. 2017. Small RNA interactome of pathogenic E. coli revealed through crosslinking of RNase E. EMBO J 36: 374-387.

Worrall JA, Howe FS, McKay AR, Robinson CV, Luisi BF. 2008. Allosteric activation of the ATPase activity of the Escherichia coli RhIB RNA helicase. J Biol Chem 283: 5567-5576.

Xu F, Lin-Chao S, Cohen SN. 1993. The Escherichia coli pcnB gene promotes adenylylation of antisense RNAI of ColE1-type plasmids in vivo and degradation of RNAl decay intermediates. Proc Natl Acad Sci 90: 6756-6760.

Zhang A, Wassarman KM, Ortega J, Steven AC, Storz G. 2002. The $\mathrm{Sm}$-like Hfq protein increases OxyS RNA interaction with target mRNAs. Mol Cell 9: 11-22.

Zhang A, Wassarman KM, Rosenow C, Tjaden BC, Storz G, Gottesman S. 2003. Global analysis of small RNA and mRNA targets of Hfq. Mol Microbiol 50: 1111-1124.

Zhang A, Schu DJ, Tjaden BC, Storz G, Gottesman S. 2013. Mutations in interaction surfaces differentially impact $E$. coli $\mathrm{Hfq}$ association with small RNAs and their mRNA targets. J Mol Biol 425: 3678-3697.

Zhang YF, Han K, Chandler CE, Tjaden B, Ernst RK, Lory S. 2017. Probing the sRNA regulatory landscape of $P$. aeruginosa: posttranscriptional control of determinants of pathogenicity and antibiotic susceptibility. Mol Microbiol 106: 919-937.

Zhao X, Koestler BJ, Waters CM, Hammer BK. 2013. Post-transcriptional activation of a diguanylate cyclase by quorum sensing small RNAs promotes biofilm formation in Vibrio cholerae. Mol Microbiol 89: 989-1002. 

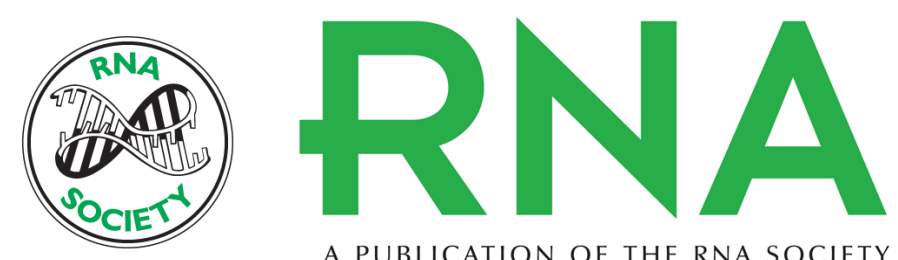

A PUBLICATION OF THE RNA SOCIETY

\section{Poly(A) polymerase is required for RyhB sRNA stability and function in Escherichia coli}

Dhriti Sinha, Lisa M. Matz, Todd A. Cameron, et al.

RNA 2018 24: 1496-1511 originally published online July 30, 2018

Access the most recent version at doi:10.1261/rna.067181.118

\section{Supplemental http://rnajournal.cshlp.org/content/suppl/2018/07/30/rna.067181.118.DC1 Material}

References This article cites 91 articles, 35 of which can be accessed free at: http://rnajournal.cshlp.org/content/24/11/1496.full.html\#ref-list-1

Open Access Freely available online through the RNA Open Access option.

Creative This article, published in RNA, is available under a Creative Commons License Commons (Attribution 4.0 International), as described at

License http://creativecommons.org/licenses/by/4.0/.

Email Alerting Receive free email alerts when new articles cite this article - sign up in the box at the Service top right corner of the article or click here.

To subscribe to $R N A$ go to:

http://rnajournal.cshlp.org/subscriptions

(C) 2018 Sinha et al.; Published by Cold Spring Harbor Laboratory Press for the RNA Society 